\title{
On the relationship between strain rate and seismicity in the India-Asia collision zone: implications for probabilistic seismic hazard
}

\author{
V.L. Stevens ${ }^{\oplus 1}$ and J.-P. Avouac ${ }^{\oplus 2}$ \\ ${ }^{1}$ Geological Sciences Department, University of Cape Town, Rondebosch 7700, South Africa. E-mail: victoria.stevens@uct.ac.za \\ ${ }^{2}$ Geological and Planetary Sciences, California Institute of Technology, Pasadena, CA 91125, USA
}

Accepted 2021 March 9. Received 2021 March 1; in original form 2020 November 8

\begin{abstract}
SUMMAR Y
The increasing density of geodetic measurements makes it possible to map surface strain rate in many zones of active tectonics with unprecedented spatial resolution. Here we show that the strain tensor rate calculated from GPS in the India-Asia collision zone represents well the strain released in earthquakes. This means that geodetic data in the India-Asia collision zone region can be extrapolated back in time to estimate strain buildup on active faults, or the kinematics of continental deformation. We infer that the geodetic strain rates can be assumed stationary through time on the timescale needed to build up the elastic strain released by larger earthquakes, and that they can be used to estimate the probability of triggering earthquakes. We show that the background seismicity rate correlates with the geodetic strain rate. A good fit is obtained assuming a linear relationship $(\dot{N}=\lambda \cdot \dot{\epsilon}$, where $\dot{N}$ is the density of the rate of $M_{\mathrm{w}} \geq 4$ earthquakes, $\dot{\epsilon}$ is strain rate and $\lambda=2.5 \pm 0.1 \times 10^{-3} \mathrm{~m}^{-2}$ ), as would be expected from a standard Coulomb failure model. However, the fit is significantly better for a non-linear relationship $\left(\dot{N}=\gamma_{1} \cdot \dot{\epsilon}^{\gamma_{2}}\right.$ with $\gamma_{1}=2.5 \pm 0.6 \mathrm{~m}^{-2}$ and $\left.\gamma_{2}=1.42 \pm 0.15\right)$. The $b$-value of the Gutenberg-Richter law, which characterize the magnitude-frequency distribution, is found to be insensitive to the strain rate. In the case of a linear correlation between seismicity and strain rate, the maximum magnitude earthquake, derived from the moment conservation principle, is expected to be independent of the strain rate. By contrast, the non-linear case implies that the maximum magnitude earthquake would be larger in zones of low strain rate. We show that within areas of constant strain rate, earthquakes above $M_{\mathrm{w}} 4$ follow a Poisson distribution in time and and are uniformly distributed in space. These findings provide a framework to estimate the probability of occurrence and magnitude of earthquakes as a function of the geodetic strain rate. We describe how the seismicity models derived from this approach can be used as an input for probabilistic seismic hazard analysis. This method is easy to automatically update, and can be applied in a consistent manner to any continental zone of active tectonics with sufficient geodetic coverage.
\end{abstract}

Key words: Earthquake hazards; Fractures, faults, and high strain deformation zones; Seismicity and tectonics; Asia.

\section{INTRODUCTION}

According to current best practice (e.g. Gerstenberger et al. 2020), the determination of a seismicity model for probabilistic seismic hazard assessment is a rather cumbersome process that requires combining data of various nature, including seismicity catalogues, palaeoseismological observations, active faults maps, fault slip-rates and geodetic strain rates, with expert judgement. A key reason for the need to combine these various data is that known past seismicity cannot be considered representative of future seismicity, in particular because the return period of devastating events generally exceeds the period of time covered by historical accounts, and even more so instrumental records. The complexity of the process has defied any standardization, and incorporation of uncertainties is a challenge. As a result, the revision of such seismicity models is a major endeavor requiring inputs from many disciplines, with the risk of significantly different outputs from one iteration to the next. 

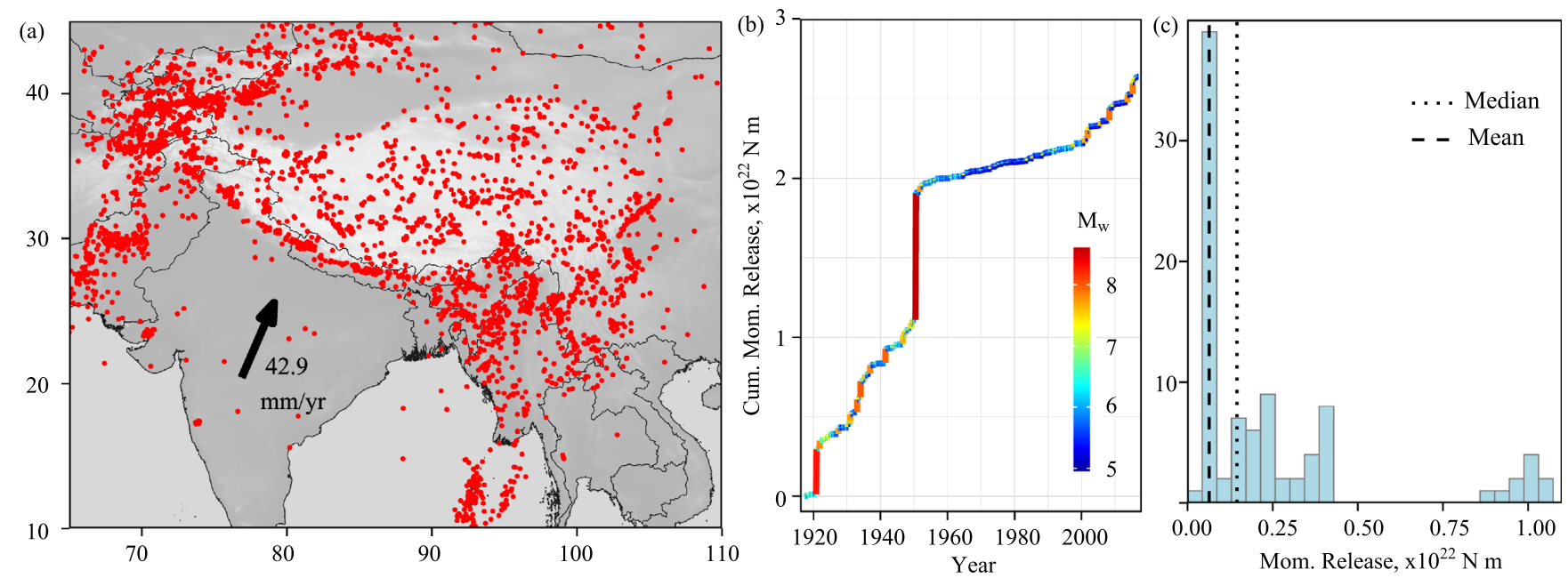

Figure 1. (a) Study area showing $100 \mathrm{yr}$ of earthquakes from the ISC-GEM catalogue, 1917-2016, in red (Storchak et al. 2013, 2015; Di Giacomo et al. 2018). Arrow shows the plate motion of India with respect to stable Eurasia (DeMets et al. 2010). (b) Cumulative moment release for earthquakes from this catalogue. (c) Histogram of total moment release for different 10-yr periods sampled from this catalogue.

In this study, we assess a simpler approach that incorporates seismicity and geodetic strain data. Now that GPS geodesy has emerged as a major tool to investigate crustal deformation (e.g. Blewitt 2007), and thanks to the effort of many institutions around the world, it is now possible to produce relatively detailed strain rate maps of actively deforming regions. The geodetic data can indeed be used to monitor interseismic strain rate buildup on active faults, and this information can be used to constrain seismic hazard models (e.g. Ward 1998; Bird \& Liu 2007; Shen et al. 2007; Bird et al. 2010; Riguzzi et al. 2012; Stevens \& Avouac 2015, 2016; Rhoades et al. 2017; Rollins \& Avouac 2019; Zheng et al. 2018; Wang \& Shen 2020). The method presented here adopts this principle, but differs from these previous studies in that the seismogenic zones are derived directly from the geodetic observations. The characteristics of each seismogenic zone, namely the magnitude-frequency distribution of potential earthquakes, are next derived jointly from the seismicity and the geodetic data. Our method does not require an analyst to define and characterize active faults or presumed homogeneous zones of distributed seismicity.

Hereafter, we first describe the rationale for the proposed approach, and then apply it to the India-Asia collision zone (Fig. 1), where seismic hazard is a major concern. We use this particular case-example to verify the assumptions made to justify our rationale, and compare the resulting hazard maps with those obtained in previous studies using a more traditional approach (Nath \& Thingbaijam 2012; Anon. 2015; Pagani et al. 2018; Stevens et al. 2018). We show that, with appropriate geodetic data and seismicity available, our method provides a simple way to determine easily updatable seismicity models which can be used for probabilistic seismic hazard assessment.

\section{METHOD, PRINCIPLES AND ASSUMPTIONS}

We adopt a generalized form of Reid's elastic rebound theory (Reid 1910), according to which an earthquake releases the elastic strain that had built up prior to its occurrence: we assume that earthquakes release, on average over the long term, the elastic strain that had built up between their occurrence. So we do not mean the notion to imply periodicity, slip predictability nor time predictability. When integrated over a certain area encompassing many faults, and over a chosen period of time, the theory translates into the moment conservation principle (Kagan 2002b). In this framework, geodetic data are used to constrain the rate of elastic strain buildup and place constraints on the rate of seismic moment release over the long-term average (e.g. Kagan 2002b; Bird \& Liu 2007; Rong et al. 2014; Avouac 2015; Bird et al. 2015; Zheng et al. 2018). In our application of this principle, we make the following assumptions.

H1: The stress rate on seismogenic crustal faults is proportional to the geodetic strain rate. The stress field is spatially heterogeneous, as shown by the variability of earthquakes focal mechanism, for example in the India-Asia collision zone (e.g. Molnar \& Lyon-Caent 1989). This hypothesis holds only if the geodetic data have enough spatial resolution to represent the elastic loading of faults given the heterogeneities of the stress field. If this condition is met, the stress rate is proportional to the geodetic strain if interseismic strain is entirely elastic. Some fraction of the geodetic strain rate might actually be anelastic. Stable frictional sliding on faults, or distributed pressure solution creep, could, for example, contribute to the deformation within the seismogenic depth range. So this hypothesis holds if anelastic strain is negligible or accounts for a constant fraction of the geodetic strain.

H2: Interseismic loading is stationary. The pattern of interseismic strain rate is derived from modern geodetic measurements, which generally do not cover more than a couple of decades. We assume that the measured geodetic strain rate is representative of the loading distribution and rate that drove past earthquakes, which are used to construct the seismicity model, and that will drive future earthquakes. The hypothesis that interseismic strain is stationary is supported by the consistency of geodetic and geological measurements of slip rate on a number of continental faults (e.g. Meade et al. 2013), in particular in the India-Asia collision zone (e.g. Stevens \& Avouac 2015; Zheng et al. 2017). However, there are counter-examples (e.g. Peltzer et al. 2001; Dixon et al. 2003; Bennett et al. 2004; Friedrich et al. 2004; Niemi et al. 2004; 
Dolan et al. 2007; Oskin et al. 2008; Ganev et al. 2012). One possible explanation for these counter-examples is that high deformation rate would switch from one fault to the other. For example, Peltzer et al. (2001) found that strain accumulation rate in the East California Shear Zone is currently three times its average, and the Garlock fault shows no evidence of current strain accumulation although it has slipped by $7 \mathrm{~mm} \mathrm{yr}^{-1}$ on average over the Holocene. This and other examples suggest that interaction between faults could induce significant temporal variations of strain rates. The mechanisms responsible for such interactions are not well understood. Viscoelastic processes can result in non-stationary reloading when one single fault is considered (e.g. Dixon et al. 2003; Kenner \& Simons 2005; Lundgren et al. 2009; Perfettini \& Avouac 2004b; Tong et al. 2014) and could potentially allow for fault interactions and clustering of large earthquakes at the regional scale (Chéry et al. 2001).

This issue has been discussed mostly based on the comparison of geological and geodetic rates. Here, we take another approach based on the comparison of geodetic rates with background seismicity rates in the India-Asia collision zone. Earthquakes release elastic strain built up over a duration much longer than the period covered by geodetic measurements. As a result, temporal variations of strain rate tensor, as a tensor quantity, would reflect in geometric inconsistencies between the geodetic strain and coseismic strain.

H3: The rate of earthquake nucleation is proportional to the stress rate. Such a proportional relationship is expected if earthquake triggering is instantaneous, as is the case with the standard Coulomb failure model (Ader et al. 2014). It is, however, well established that earthquake nucleation is a time-dependent process, as is evident, for example, from the weak to insignificant correlation between earthquakes and Earth tides (Vidale et al. 1998). The nucleation time is thus probably not negligible at the $\sim 12 \mathrm{hr}$ timescale of earth tides (Beeler 2003), but the correlation between seismicity and seasonal stress variations (Bettinelli et al. 2008; Johnson et al. 2017), or between post-seismic deformation and seismicity following large earthquakes (Perfettini \& Avouac 2004b; Lange et al. 2014), suggests that it is negligible at the annual timescale. More sophisticated nucleation models than the standard Coulomb failure model can be used to derive the relationship between seismicity and stress rate, using, for example, the rate-and-state friction formalism (Dieterich 1994; Heimisson \& Segall 2018). With such a model, the seismicity rate is still proportional to the stress rate if the loading rate is constant or varies at a timescale longer than the nucleation time (Ader et al. 2014). Therefore our hypothesis holds if the loading rate is assumed constant or to vary slowly. It would not be applicable to the case of a loading rate varying at a subannual timescale, as can happen in the case of seismicity induced by human activity.

H4: The density of faults on which earthquakes can nucleate is uniform in space. One might expect that the density of nucleation sites would depend on local properties related to the tectonic history, lithology and thermal structure, but we will see that this hypothesis is nonetheless verified in the case-example considered here.

H5: Earthquakes are triggered either by the quasi-static buildup of stress due to interseismic loading or by the stress changes induced by previous earthquakes. This hypothesis means that the seismicity can be separated into two populations: the background seismicity, which is driven by interseismic loading, and aftershocks. This essentially bimodal nature of seismicity is revealed in plots showing the distribution of interevent time intervals and distances (Zaliapin \& Ben-Zion 2013) and is the basis of models of seismicity such as ETAS (Ogata 1988), which have been shown to reproduce seismicity catalogues very satisfactorily (Marsan \& Lengliné 2008; Hainzl \& Christophersen 2017; Helmstetter et al. 2006).

H6: The background seismicity is assumed to result from a Poisson process. It is indeed commonly assumed that earthquakes not triggered by other earthquakes follow a Poisson process as suggested by Gardner \& Knopoff (1974). However, in reality whether this hypothesis is verified or not depends on the declustering technique and parameters used to extract the background seismicity (Luen \& Stark 2012).

H7: Seismicity follows the Gutenberg-Richter law (G-R, Gutenberg \& Richter 1944), which states that the number of earthquakes with magnitude larger than $M, N(>M)$, over a certain period in a given seismogenic volume and up to the maximum magnitude, $M_{\text {max }}$, obeys

$\log _{10}(N(>M))=a-b \cdot M,\left(M<M_{\max }\right)$.

Alternative formulations to this truncated G-R model could be adopted by assuming some form of tapering of the distribution at large magnitude (e.g. Kagan 2002a).

We detail below how, based on these hypotheses, geodetic measurements of interseismic strain can be used to construct a seismicity model suitable for probabilistic seismic hazard assessment, taking the particular example of the India-Asia collision zone.

\section{SETting OF STUDY AREA AND GEODETIC STRAIN RATES}

In this section, we present the setting of our study area, the strain rate map produced from our compilation of geodetic data, the seismicity data and the correlation with the strain rate map.

The India-Asia collision zone is a particularly good area to analyse the relationship between seismicity and geodetic strain given the sheer size of the deforming area, the intense seismic activity, the diversity of focal mechanisms and the recent accumulation of geodetic measurements (see references in Supporting Information). A number of studies have combined geodetic and geological slip rates, and seismicity, to determine the pattern and rates of crustal deformation in the area (e.g. Holt et al. 2000; England \& Molnar 2005; Delescluse \& Chamot-Rooke 2007). We do not repeat or revisit such studies, but aim, in addition to investigating the relationship between seismicity rate and strain rates, to assess the assumption underlying these studies that the strain rate field is stationary.

Geodetic data were collected over the past $\sim 30 \mathrm{yr}$. They show the pattern of deformation induced by the $\sim 4 \mathrm{~cm} \mathrm{yr}^{-1}$ (DeMets et al. 2010) indentation of India into Eurasia which is driving intense seismicity with occasional, very large events. The largest intracontinental 

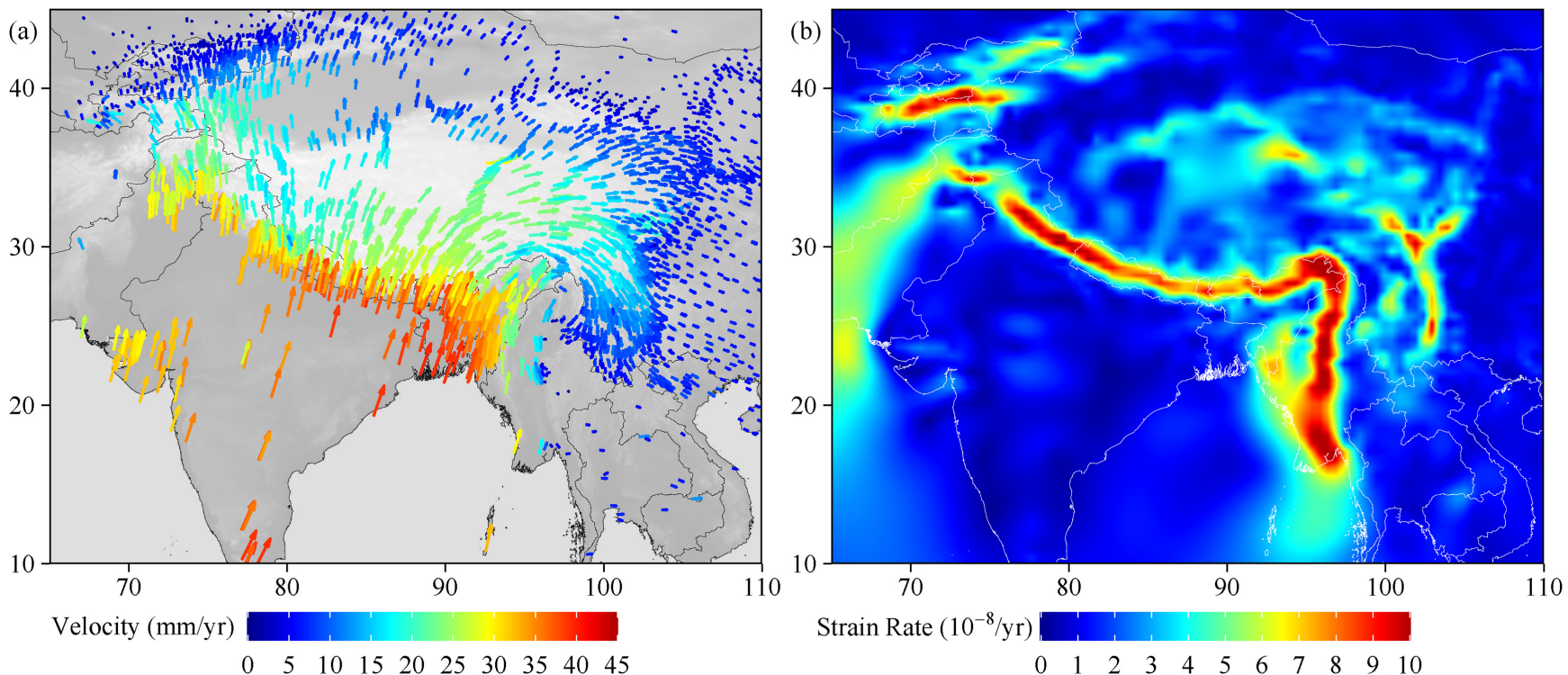

Figure 2. (a) GPS velocities in the Eurasia-fixed reference frame used in this study (see Supporting Information for the data sources). (b) Second invariant of the strain rate tensor for the region of interest calculated from GPS data.

earthquake ever recorded, the $M_{\mathrm{w}} 8.7$ Assam earthquake of 1950 (Molnar \& Qidong 1984), occurred at the eastern end of the Himalayan arc, and similar large earthquakes have probably occurred elsewhere according to palaeoseismic studies (e.g. Lavé et al. 2005; Kumar et al. 2006, 2010; Bollinger et al. 2014). The return period of large events $\left(M_{\mathrm{w}}>8\right)$ in the Himalaya, where strain rates are particularly fast, probably exceeds many centuries (Stevens \& Avouac 2016). In areas with lower strain rate, the large events have probable return periods exceeding many thousands of year, as for example along the Longmenshan which was struck by the devastating Sichuan $M_{\mathrm{w}} 7.9$ earthquake of 2008 (e.g. Liu-Zeng et al. 2009). As a result, the time history of moment release, even integrated over the large area considered here, is very erratic (Fig. 1b) and the seismic moment released over $10 \mathrm{yr}$ varies by many orders of magnitude depending on the decade chosen over the last century (Fig. 1c). Therefore, we cannot assume that the largest earthquake in a short instrumental catalogue, or even a 100-yr catalogue, is the maximum magnitude earthquake that can occur. Instead, we can use moment conservation to estimate $M_{\max }$. Using the observed seismicity together with the GPS can help us derive seismicity models that balance moment buildup and release.

We consider the region of latitude $10-45^{\circ}$ and longitude $65-110^{\circ}$, which covers the zone of deformation resulting from the India-Asia collision (Fig. 2). It includes the Himalaya and Tibetan Plateau, as well as the Tian Shan. We use 3203 GPS measurements compiled from the literature, all rotated into the fixed-Eurasian reference frame (Fig. 2a, see Supporting Information for references). The geodetic data were corrected for the coseismic steps due to large earthquakes $\left(M_{\mathrm{w}} \geq 7.5\right)$. The data spans varying time periods, with the oldest GPS data dating from 1994.

We used the method of Tape et al. (2009) to determine the horizontal strain rate field. We also tested the method of Shen et al. (2015), and present the results in Fig. S1. The analysis confirms the results presented in the main text based on the method of Tape et al. (2009). This method uses multiscale wavelets to adapt locally the resolution to the density of geodetic observations. We use a $q$-value of 8 , which corresponds to a minimum scale value of $28 \mathrm{~km}$. Strain variations at a smaller scale are not resolvable with the current density of geodetic measurements. The second invariant of the horizontal strain rate tensor is plotted in Fig. 2(b). The zones of higher strain rate correlate relatively well with known active faults (Styron et al. 2010, Fig. 3), suggesting that the heterogeneities of geodetic strain reflect strain localization at the lithospheric scale associated with crustal faults. The Himalaya clearly stand out as a continuous strip of higher strain rate where the strain rate peaks at $\sim 10^{-7} \mathrm{yr}^{-1}$. The shortening rate across the range matches the slip rate on the Main Himalayan Thrust at the few sites where both determinations can be compared, implying that, in the particular case of the Himalayas, the geodetic strain rate must be essentially elastic (e.g. Stevens \& Avouac 2015).

The high strain rate strip can be seen bending around the eastern and western syntaxes. South of the eastern syntax, a zone of localized higher strain rate coincides with the north-south striking right-lateral Sagaing Fault, and becomes more diffuse southward (Wang et al. 2011; Sone Aung et al. 2016). The Tian Shan can also be seen as a region of fairly high strain rate. On the eastern edge of the Tibetan Plateau, from South to North, the Xianshuihe-Xiaojiang, Kunlun and Haiyuan strike-slip faults can be made out. The Altyn Tagh can also been faintly seen, bordering the northwest edge of the plateau, though there are fewer GPS stations in this region, which perhaps is why it is less prominent. The slightly increased areas of strain rate heading north perpendicular to the Main Himalayan Thrust coincide with extensional N-S trending grabens. Southwest of the western syntax, there are rather few GPS points, which is the cause of the ill-defined broad area of larger strain rate associated with the left-lateral strike-slip faults, including the Chaman and Ghazaband faults. These faults are the symmetrical equivalent of the Sagaing fault system and accommodate the northward motion of India. 


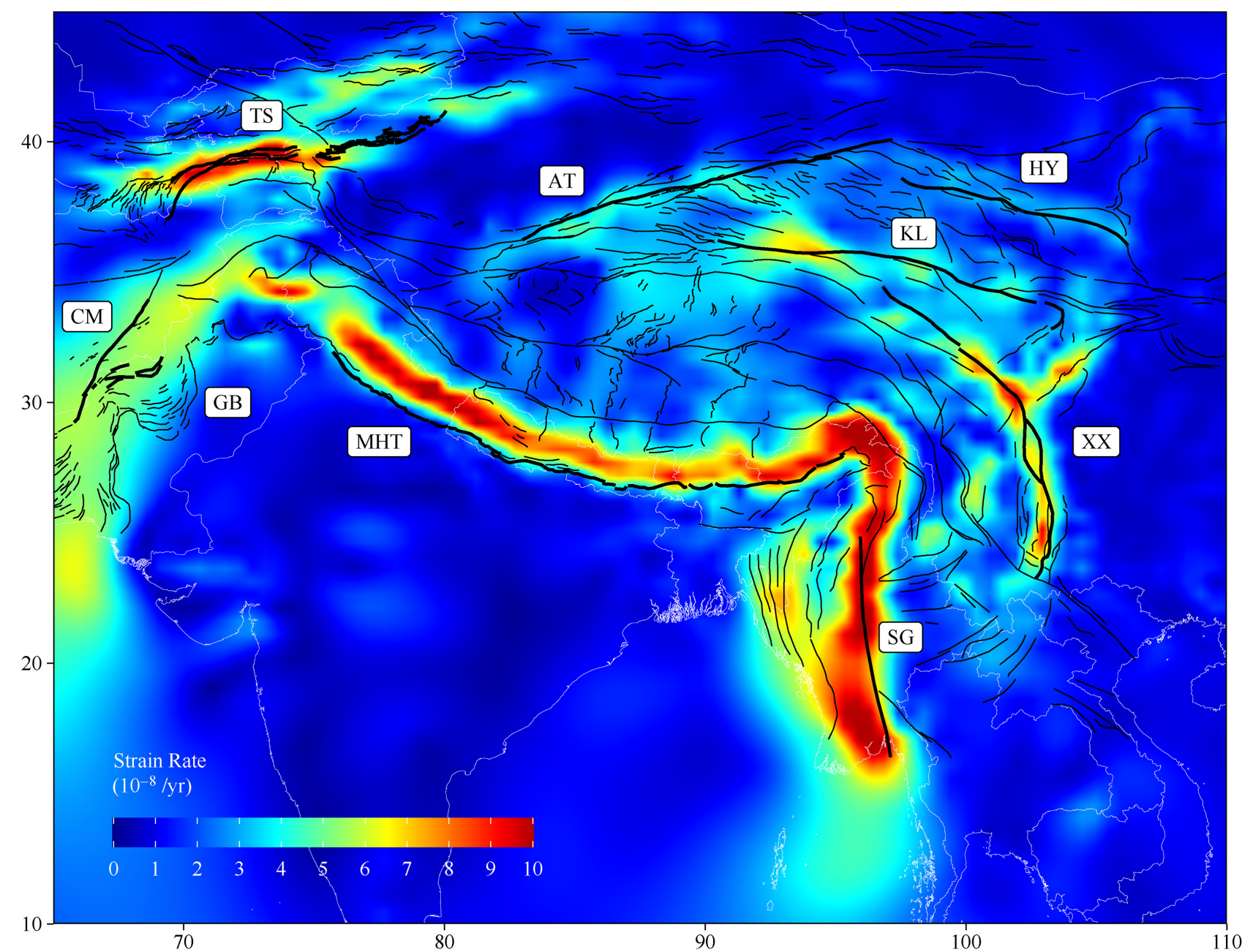

Figure 3. Strain rate map as in Fig. 2(b), with active faults superimposed in black, from Styron et al. (2010). MHT, Main Himalayan Thrust; AT, Altyn Tagh; TS, Tian Shan; XX, Xianshuihe-Xiaojiang; KL, Kunlun; HY, Haiyuan; SG, Sagaing, CM, Chaman; GB, Ghazaband.

\section{COMPARISON OF GEODETIC STRAIN WITH SEISMIC MOMENT TENSORS}

To assess whether the GPS measurements are dense enough, and representative of the accumulated elastic strain that earthquakes release, we compare geodetic strain rate tensors with the coseismic strain release tensors. We use the GCMT catalogue from 1976 to 2020 (Dziewonski et al. 1981; Ekström et al. 2012). The smallest earthquake is $M_{\mathrm{w}} 4.6$ and the largest is the 2008 Sichuan $M_{\mathrm{w}}$ 7.9. To maximize the spatial coverage we did not impose any threshold magnitude. The catalogue is probably inhomogeneous due to the varying density of seismometers and reporting practices. However, here we are evaluating seismic strain, which is dominated by the largest earthquakes, so the possible spatial bias should minor. To verify this inference we determined the magnitude of completeness $\left(M_{\mathrm{w}} 5\right)$ and found that the 22 per cent earthquake below this cut-off were apparently randomly distributed. Therefore we do not expect any bias introduced by our choice of not thresholding magnitude. We select earthquakes with hypocentral depth shallower than $50 \mathrm{~km}$ depth and this leaves 1797 earthquakes, out of 2277 in total.

As explained above, the rationale is that the moment tensor of earthquakes must reflect the ambient tectonic stresses, hence the result of stress buildup over a period comparable to that needed to balance the coseismic stress drop due to previous events. The stress drop during an earthquake is typically between 1 and $10 \mathrm{MPa}$, and the shear modulus is typically $30 \mathrm{GPa}$; it follows that the shear strain drop during an earthquake is of the order of $3 \times 10^{-5}$ to $3 \times 10^{-4}$ (Kanamori \& Brodsky 2004). Given that strain rates are on the order of $10^{-8}$ to $10^{-7} \mathrm{yr}^{-1}$, it takes on the order of 100 to $10000 \mathrm{yr}$ of interseismic loading to balance coseismic strain at a given location. The GCMT seismic catalogue, which covers only $44 \mathrm{yr}$, is certainly not representative of the long-term average seismicity. In that case, it makes sense to compare coseismic and geodetic strain tensors with regards to their orientation and aspect ratio, but not in terms of their amplitudes.

We calculate earthquake strain tensors using Kostrov's approach (Kostrov 1974), which is commonly used to estimate the mean strain tensor of the volume containing the faults activated by a collection of earthquakes (e.g. Holt et al. 1995). The original formula is not strictly correct, as demonstrated by Carafa et al. (2017). However, the revision implies only a rescaling of the tensor and does not affect the determination of the principal directions nor the ratio of the principle values of the seismic moment tensor, which are the quantities entering 

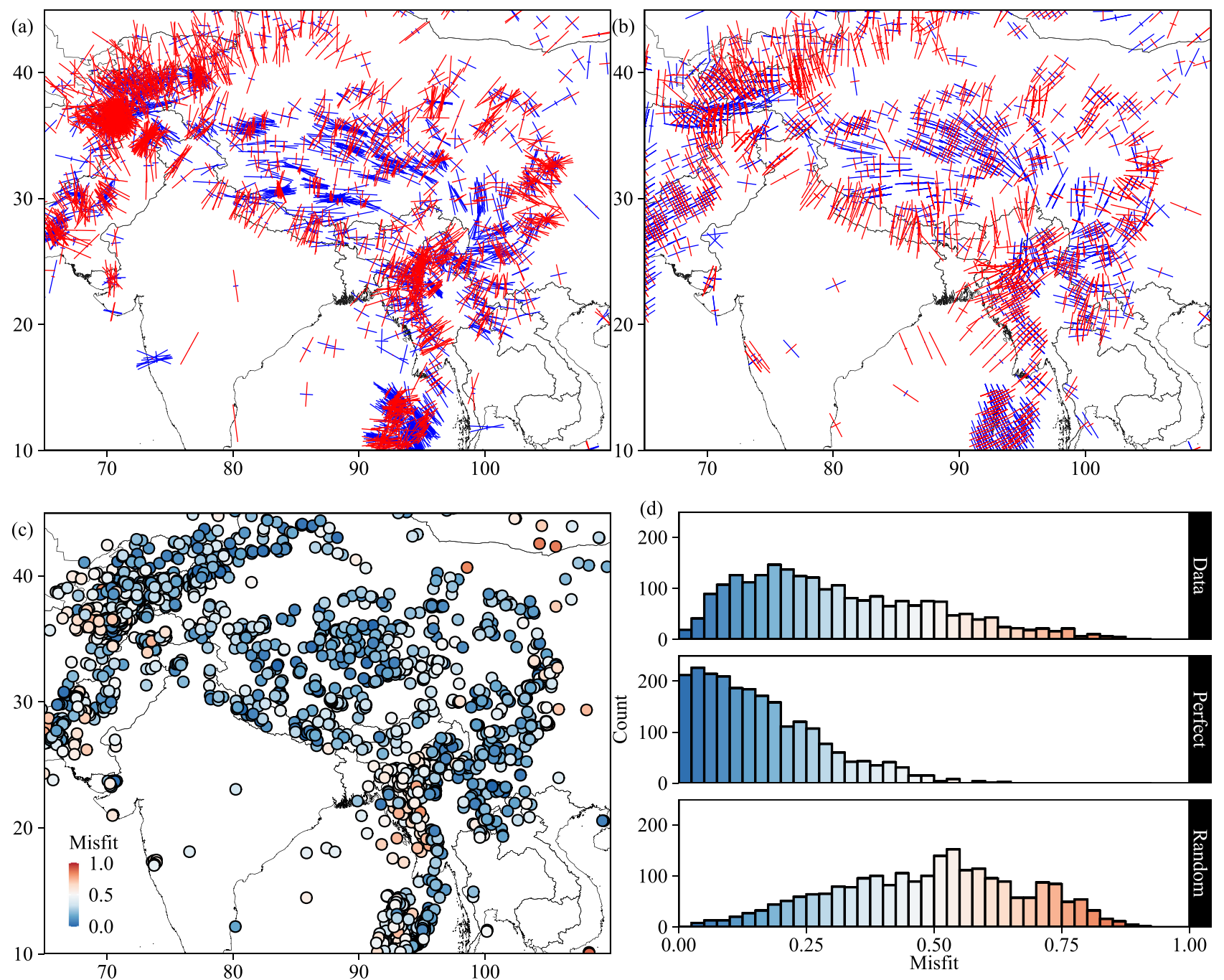

Figure 4. Comparison of directions of principal horizontal strains. Red lines show direction of maximum compression and blue lines show direction of maximum extension. (a) Moment tensor solutions. (b) GPS strain rate map. (c) Euclidean norm distribution. (d) Probability density functions (PDFs) of Euclidean norm misfits between the strain tensors derived from seismicity and the geodetic strain rates for the Data, for a 'Perfect' fit (perfectly collinear plus a standard deviation of $0.13 \pm 0.075$ ) and for a Random distribution. The median misfits are $0.31,0.16$ and 0.51 , respectively.

our analysis. One can use this method to compare geodetic strain with some average coseismic strain within an area defined by the distribution of GPS station, typically using a triangular meshing (e.g. Masson et al. 2005). This approach requires some weighting. If the weighting is based on moment, as it should be if the catalogue was long enough to represent the long-term seismicity, a few larger earthquakes can have an overwhelming contribution. Here we choose to compare the geodetic strain estimated at the location of each earthquake with its moment tensor, so we apply Kostrov's method for a volume that contains only one event. In this case, the coseismic strain tensor is proportional to the moment tensor. Because we only compare the shape of the tensors, there is not need to specify a volume.

For every earthquake, the directions of horizontal principal strains are determined and compared with those from the GPS strain rate map (Fig. 4). We find that the directions of principal strains and their ratio, calculated from both earthquakes and from the GPS strain rate field, are very similar. Both show strong compression perpendicular to the Himalayan arc, with very small extension parallel to the arc. In the Tibetan Plateau itself, there is significant east-west extension and only very minor north-south compression.

We use the Euclidean norm (the square root of the sum of the squared differences of each element in the strain rate tensor) to quantitatively compare the normalized geodetic strain rate tensor and strain tensor derived from the seismic moment tensors:

$\|x-y\|_{F}=\sqrt{\sum_{i=1}^{m} \sum_{j=1}^{n}\left|x_{i j}-y_{i j}\right|^{2}}$,

where $\|x-y\|_{F}$ is the Euclidean norm of the difference between the two matrices with components $x_{i j}$ and $y_{i j}$, normalized so that both $x_{i j}$ and $y_{i j}$ have a Euclidean norm of 1. 
Because geodetic and seismic strain tensors are normalized to unity, only the directions and the ratio of principal values are actually compared. It can be seen that the misfit is in general small, and randomly distributed across the area. There is thus agreement between earthquakes' strain release and GPS strain rate. To test that the agreement is significant, we verify that the misfits are overall much smaller than what would be expected from a random distribution of moment tensors. To estimate this we redistribute the earthquakes randomly over the study area 1000 times, and for each randomized distribution, we calculate the histogram of Euclidean norms, with one example shown in Fig. 4d. For the randomized distributions, the probability of obtaining a median misfit lower than the one obtained with the actual distribution of earthquakes $(\sim 0.27)$ is less than 1 per cent.

We also estimate the misfit that is expected in the case of a perfect match between the geodetic and the seismic strain tenors, given the uncertainties on the moment tensors and on the GPS strain rates. To do so, we assume that nearby measurements, that is at distances less than $100 \mathrm{~km}$ (the typical distance between nearby GPS stations), can be considered to represent independent measurements of the same quantity. We then calculate the standard deviation of the Euclidean distance between all different groupings of nearby data, and use this result to add errors to perfectly fitting data, to simulate earthquakes that 'perfectly' fit the GPS strain rate data within uncertainties (Fig. 4d). This calculation shows that the misfits between the seismic moment tensors and the geodetic strain rate tensors are significantly larger than expected if the tensors were perfectly collinear, taking into account the data uncertainties.

The larger scatter in the earthquake tensor solutions suggests that the stress field probed by the earthquake mechanisms is more heterogeneous that the stress field inferred from the interseismic strain measured from geodesy. The moment tensors provide information about local strain (at the scale of the earthquake source size), while geodetic strains are averaged over relatively larger areas defined by the distribution of the geodetic measurements, so the scatter could be due to the lack of resolution of the geodetic measurements. However, factors other than interseismic strain can cause stress heterogeneities. These stress heterogeneities could be due to, for example, topographic stresses or local heterogeneities in the elastic medium and variations in fault friction (Rivera \& Kanamori 2002; Bollinger et al. 2004; Fialko et al. 2005). Earthquakes themselves change the stress-field locally and must cause time-dependent heterogeneities of stresses. These effects are probably dominant causes for the observed level of misfit. We however consider that the agreement between the seismic moment tensor and the geodetic strain tensor is sufficient to lend support to hypotheses H1 (stress rate is proportional to geodetic strain rate) and H2 (interseismic strain is stationary).

\section{DECLUSTERING AND TESTS OF POISSON DISTRIBUTION ASSUMPTION}

We look at both 10- and 100-yr earthquake catalogues. The 10-yr catalogue, extracted from the ISC catalogue (International Seismological Centre 2013), extends from 1 December 2009 to 30 November 2019. We consider only crustal earthquakes, defined as those with hypocentral depths less than $50 \mathrm{~km}$ and those with magnitudes reported either as $M_{\mathrm{w}}, M_{\mathrm{b}}$ or $M_{\mathrm{s}}$. We then use the relationships in Scordilis (2006) to convert $M_{\mathrm{b}}$ and $M_{\mathrm{s}}$ into moment magnitude, $M_{\mathrm{w}}$. The resulting data set consists of 15789 earthquakes. The two largest magnitude events in the catalogue are the 2013 Balochistan $M_{\mathrm{w}} 7.7$ and 2015 Gorkha $M_{\mathrm{w}} 7.8$ earthquakes; they account for 75 per cent of the cumulative seismic moment release over that period. We decluster the earthquakes using the Reasenberg declustering method (Reasenberg 1985), with a minimum look ahead time for non-clustered events of $1 \mathrm{~d}$, and maximum look ahead time of $100 \mathrm{~d}$. We use a confidence of 0.95 for observing the next event in a sequence. We set the factor for radius of interaction to 25 , an effective lower magnitude cut-off of 3 , set to reduce to 2 during clusters. We assume horizontal and vertical uncertainties in earthquake location to be 3 and $15 \mathrm{~km}$, respectively. After declustering we end up with 11837 earthquakes. For the analysis, we take earthquakes over the magnitude of completeness, $M_{\mathrm{c}}$, here $M_{\mathrm{c}}=4.0$, leaving 8444 earthquakes.

The 100-yr catalogue is extracted from the ISC-GEM catalogue (Storchak et al. 2013, 2015; Di Giacomo et al. 2018). We select the years 1917-2016 inclusive. This catalogue contains 3767 earthquakes between $M_{\mathrm{w}} 5$ and 8.6, with a magnitude of completeness of 6. After declustering, using the same parameters as above, we end up with 510 earthquakes above $M_{\mathrm{w}} 6$.

We show the results of declustering in Figs 5 and 6. It can be seen that the increase in total number of earthquakes over time is nearly linear after declustering (Fig. 5a). There are no longer obvious clusters of seismicity in space and time (Fig. 5b). We test declustering by comparing rescaled time and distance density plots (Zaliapin \& Ben-Zion 2013) for both the all events and declustered catalogues (Fig. 6). If the non-declustered catalogues are considered, the plots show a bimodal distribution, with the clusters of events that are closer together in space presumably corresponding to the aftershocks. For the declustered catalogues, we see a single mode suggesting that the aftershocks have been well filtered out, though perhaps some aftershocks remain in the 100-yr declustered catalogue.

We next test the assumption that the declustered seismicity is consistent with a Poisson process. We compare observed interevent times for different cut-off minimum magnitudes with the exponential distribution expected from a Poisson process (Fig. 7). We see that the declustered catalogues, for both the 10- and 100-yr periods, follow a Poisson process, when considering all earthquakes $\geq M_{\mathrm{w}} 4$ and also for only large events, for example those $\geq M_{\mathrm{w}} 6.5$. So we consider that H6 (the background seismicity results from a Poisson process) is verified reasonably well.

Even after declustering, the distribution of epicentres over the entire study area is clearly not homogeneous. This is obvious from the map view (Fig. 8), and from comparing the observed distribution of interevent distances in the declustered catalogues with the distributions of interevent distances in a random catalogue with the same total number of events generated assuming a homogenous density of events (Fig. 9). We use Ripley's K function (Ripley 1977), which is a standard test of whether points are clustered or randomly distributed: 

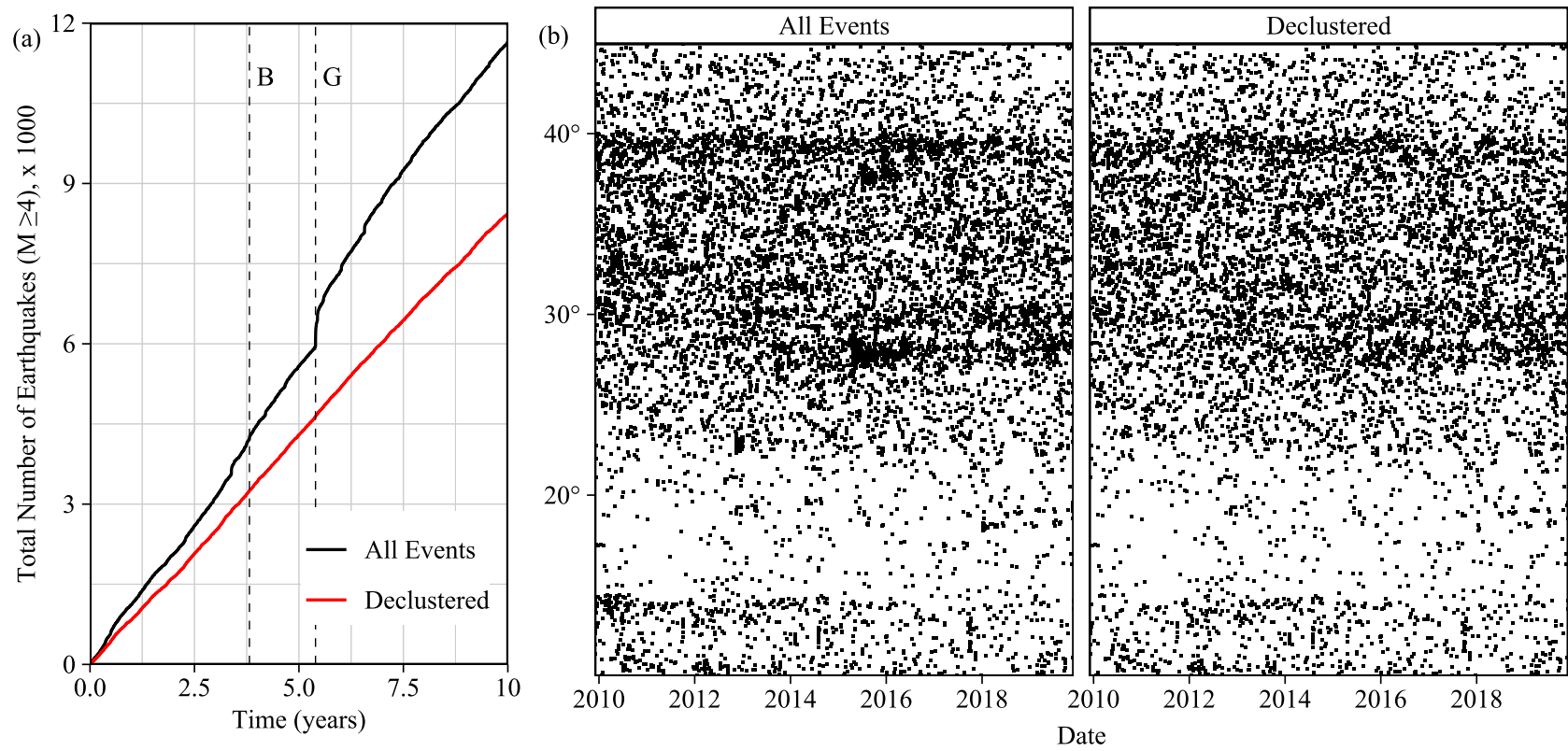

Figure 5. (a) Cumulative number of earthquakes over $10 \mathrm{yr}$, from December 2009 to November 2019 inclusive, from the ISC catalogue. The dashed lines labelled B and G show the occurrence of the 2013 Balochistan and 2015 Gorkha earthquakes respectively. (b) Latitude-date distribution of the 10-yr catalogue comparing the all events, and the declustered catalogue.

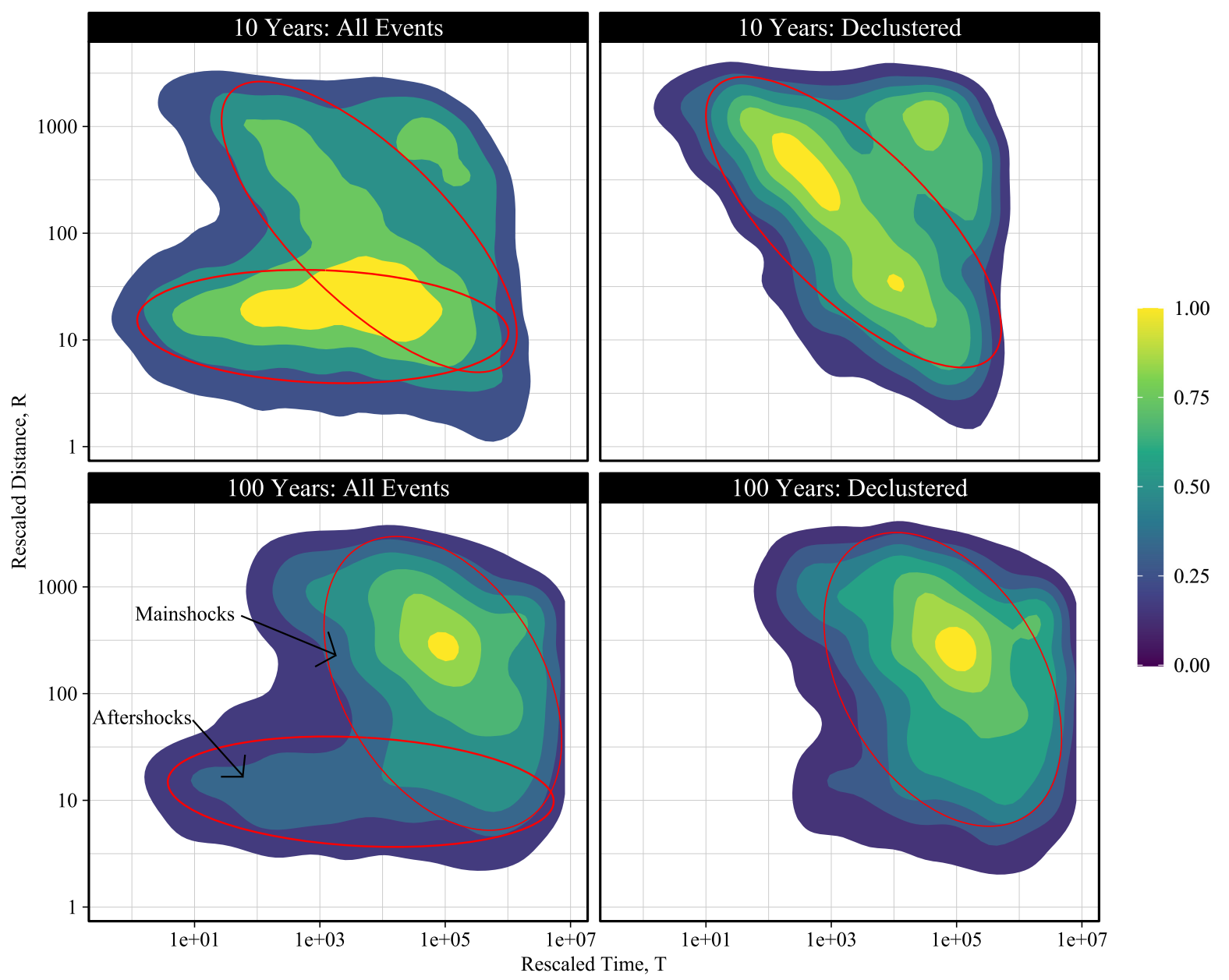

Figure 6. Rescaled space-time density plots from the declustering test of Zaliapin \& Ben-Zion (2013) for the 10- and 100-yr catalogues. 

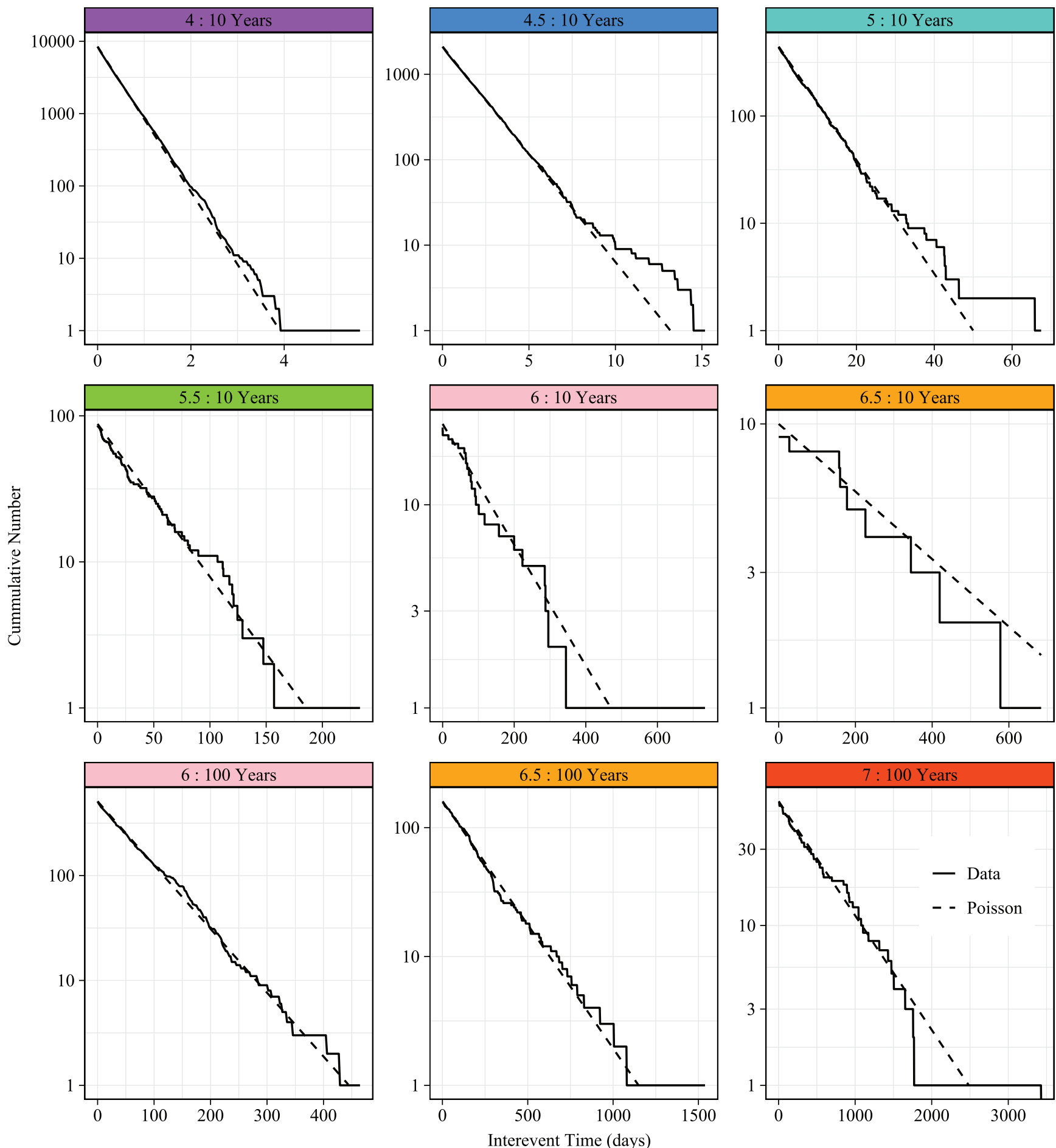

Figure 7. Comparison of observed interevent times (solid lines) versus the exponential distribution (dashed lines) expected for a Poisson process for different minimum cut-off magnitudes, for the $10 \mathrm{yr}$ (top two rows) and $100 \mathrm{yr}$ (bottom row) catalogues. The Poisson distribution is calculated from $n_{\mathrm{cp}}=N_{\mathrm{eqs}} \cdot \exp ($ $-t / t_{0}$ ), where $n_{\mathrm{cp}}$ is the cumulative number of events, $N_{\mathrm{eqs}}$ is the total number of events, $t$ is the time interval and $t_{0}$ is the mean interevent time.

$K o=\frac{1}{\lambda\left(N_{\text {eqs }}-1\right)} \times \sum_{i \neq j}^{N_{\text {eqs }}} I\left(d_{i j}<r\right)$, where $\lambda=\frac{N_{\text {eqs }}}{A}, A$ is the area, $N_{\text {eqs }}$ is the number of earthquakes within that area, $d_{i j}$ is the distance between events $i$ and $j, r$ is the search area radius and $I$ is the indicator function, such that it is 1 when the operand is true, and 0 otherwise. Our hypothesis is that the seismicity depends on the strain rate, but that within an area of uniform strain rate it is homogeneously distributed. So we carry out the same test but now considering the seismicity within bins of strain rate.

The study area is divided into regions corresponding to 10 different levels of strain rate, from 0 to $9 \times 10^{-8} \mathrm{yr}^{-1}$, with bin width $1 \times$ $10^{-8} \mathrm{yr}^{-1}$. We did not separate out regions with strain rate $\geq 10 \times 10^{-8} \mathrm{yr}^{-1}$ since they make up $\leq 0.1$ per cent of the total area, and contain too few earthquakes to be meaningful. The earthquakes from the 10 -yr declustered catalogue within each of these areas were extracted (Fig. 8 ). 


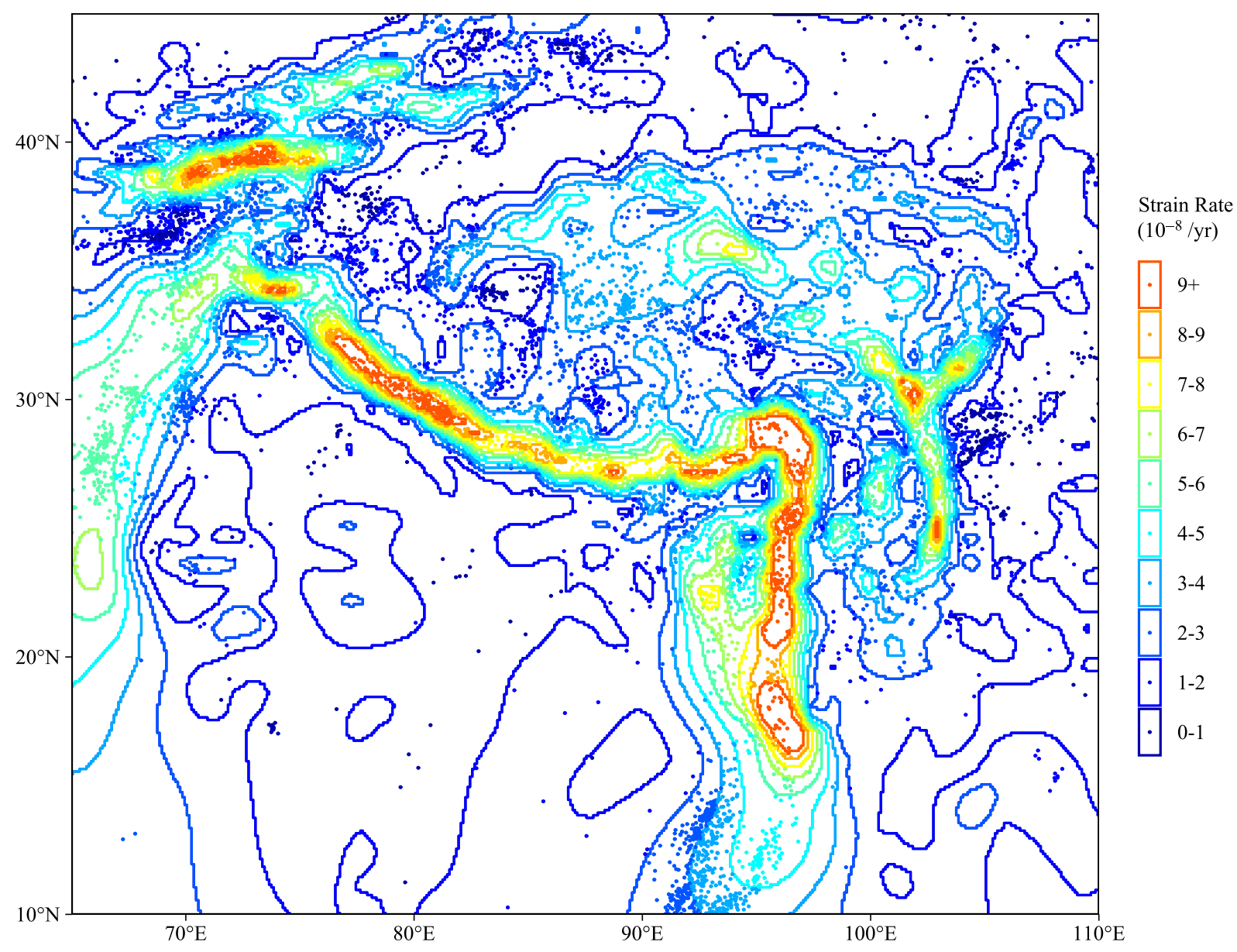

Figure 8. Plot showing boundaries of areas of different strain rate from GPS data. The contours were created through vectorization of the underlying strain rate grid, followed by smoothing using Chaikin's corner cutting algorithm (Chaikin 1974). Dots show the locations of the earthquakes from the declustered 10 -yr catalogue. Both are colour-coded by different strain rate.

Within areas of moderate to high strain rate $\left(>2 \times 10^{-8} \mathrm{yr}^{-1}\right)$ the distribution of interevent distances in the catalogue follows closely the distribution expected for a homogeneous density of probability (Fig. 9). This is not verified for the seismicity in areas of low strain rate $\left(0-2 \times 10^{-8} \mathrm{yr}^{-1}\right)$, where the catalogue is not completely spatially random. This may be because aftershocks in areas of low strain rate can last a very long time (Stein \& Liu 2009), so there could be clusters corresponding to aftershocks of main shocks that are not recorded in the instrumental catalogue, and are therefore not removed in the declustering. Another reason that could explain the inhomogeneity is that iso-contour lines of strain rate are less well constrained in areas with lower strain rate where the distribution of GPS measurements is generally sparser. In that regard, we note that the earthquakes tend to occur near the edges of the higher strain rate areas (see Fig. 2). It is also possible that, within the lower strain rate areas, spatial variation of seismicity is governed by other factors than the strain rate, and related to the local geology.

We tested different binning strategies. The results are shown in Figs S3-S5. Smaller bins yield more dispersion due to smaller data sets in each bin, but the trends observed with 10 bins are all well preserved. We find the choice of 10 bins to be a good compromise. No information is lost by oversmoothing.

In this section, we have verified $\mathrm{H} 4$ (the density of nucleation points of earthquake is uniform) and H6 (the background seismicity results from a Poisson process) for our study area, at least where the strain rate is higher than $2 \times 10^{-8} \mathrm{yr}^{-1}$. It thus seems that, within an area with a given strain rate, the background seismicity can be considered to result from a stationary Poisson process with a uniform probability of occurrence in space. In areas with strain rates less than $2 \times 10^{-8} \mathrm{yr}^{-1}$ the productivity of earthquakes does not seem homogeneous.

\section{COMPARISON WITH SEISMICITY RATE}

The rate of earthquakes in the declustered catalogue can now be assumed to represent the background seismicity rate. We now test how the seismicity rate varies with the strain rate. We again use the subdivision of the study area into 10 regions corresponding to 10 different strain rate bins (Fig. 8). In Fig. 10(a) we compare the strain rate in each region with the density of earthquake rate above the minimum cut-off magnitude, $M_{\mathrm{c}}$. We use the maximum-curvature method (e.g. Wiemer \& Wyss 2000) to find $M_{\mathrm{c}}=4$ (see Fig. S2 for magnitude-frequency 

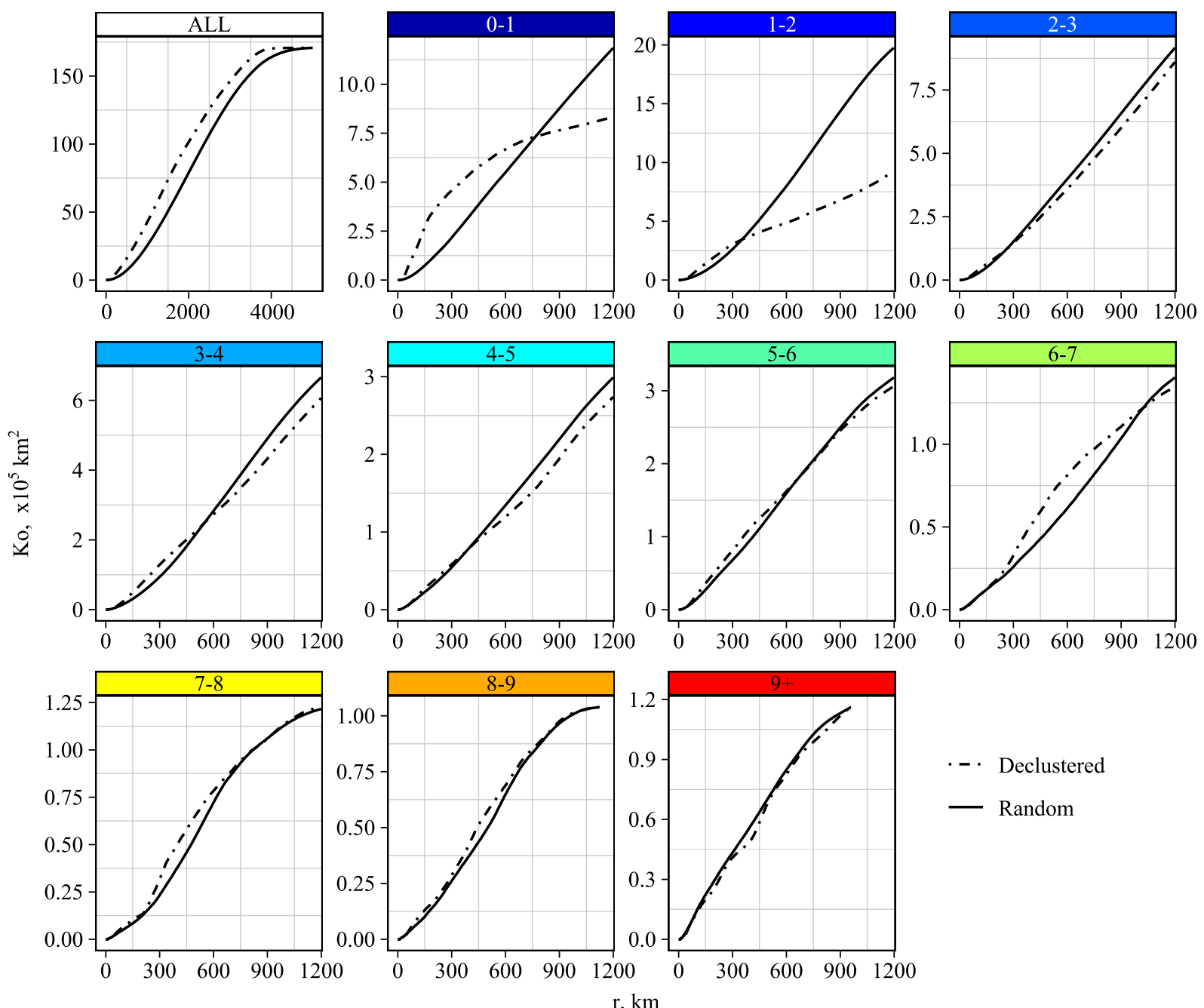

$\cdot-\cdot$ Declustered

- Random

Figure 9. Tests of homogeneity of spatial distribution. The interevent distance distribution is calculated with the declustered (dotted-dashed) catalogue and compared with the distribution expected with a spatially completely random distribution (solid line). Ko is Ripley's K function (Ripley 1977). The first panel shows that the declustered seismicity considered as a whole is not homogeneously distributed. The other panels show the same test for seismicity within bins of strain rate. Headers indicate the strain rate bin in $10^{-8} \mathrm{yr}^{-1}$. When the seismicity within bins of strain rate is considered, it is relatively homogeneous for strain rates larger than $2 \times 10^{-8} \mathrm{yr}^{-1}$.

distributions). We see that the higher the strain rate, the higher the rate of earthquakes. This correlation is much higher than what could result from chance, as can be seen by comparing the coloured dots with the grey lines in the figure. The grey lines show the density of earthquake rate found per strain rate bin from 100000 realizations of earthquakes randomly distributed across the entire area, that is if there was no dependence on strain rate. At face value the correlation suggests a possible non-linear relationship. Because we would expect a linear relationship for a population of faults obeying a standard Coulomb failure model with constant stress drop, we determine a best fitting linear relationship between the density of earthquake rate and strain rate:

$\dot{N}=\lambda \cdot \dot{\epsilon}$,

where $\dot{N}$ is the density of earthquake rate in $\mathrm{m}^{-2} \mathrm{yr}^{-1}$, and $\dot{\epsilon}$ is strain rate expressed in $\mathrm{yr}^{-1}$. The constant is estimated to be $\lambda=2.5 \pm 0.1 \times$ $10^{-3} \mathrm{~m}^{-2}$ for $M_{\mathrm{w}} \geq 4$ events.

The $R$-value is 0.92 . Assuming a power-law relationship, we get a slightly higher $R$-value of 0.96 with

$\dot{N}=\gamma_{1} \cdot \dot{\epsilon}^{\gamma_{2}}$,

where $\gamma_{1}=2.5 \pm 0.6 \mathrm{~m}^{-2}$ and $\gamma_{2}=1.42 \pm 0.15$. Using the $F$-test we find that the improvement of fit is significant at the 95 per cent level when we add a second parameter.

We test a second method of computing strain, developed by Shen et al. (2015, Fig. S1), and recalculate the density of earthquake rate within each strain rate bin. We find a similar correlation between strain rate and earthquake rate up to the highest two strain rate bins (Fig. S3), showing that the correlation is real. Unlike the Tape et al. (2009) method, the Shen et al. (2015) method does not preserve the continuity of strain rate along the Himalayan arc suggested by the data themselves. 

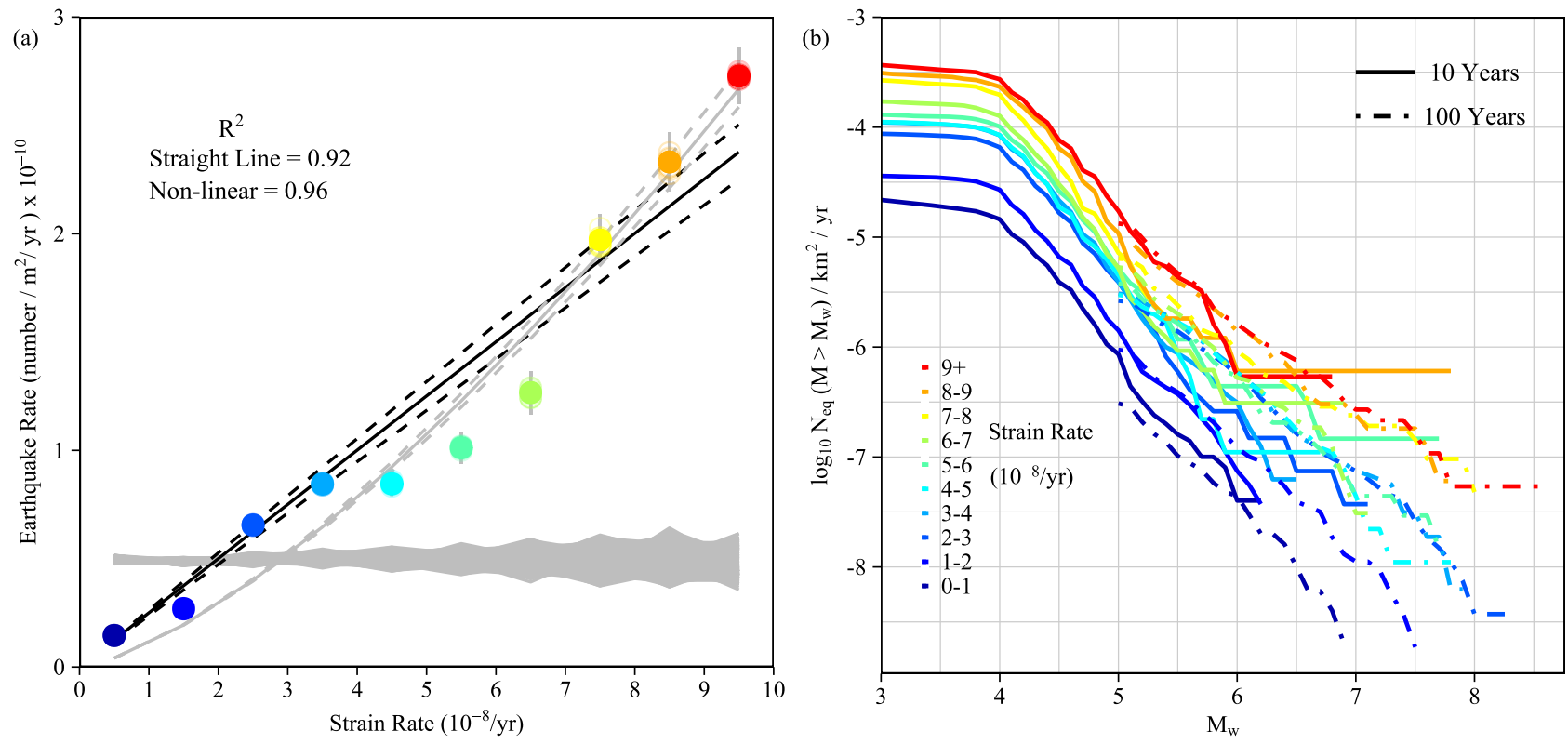

Figure 10. (a) Comparison of density of earthquake rate $\left(M_{\mathrm{W}} \geq 4\right)$ and geodetic strain rate. Coloured dots correspond to discrete regions of different strain rate levels. Coloured empty circles, which are mainly overlapping due to the small spread, show the effect of varying the epicentres within a circle of radius $10 \mathrm{~km}$, to show how uncertainties in epicentre location may affect the results. Grey lines show 100000 realizations of randomized distributions of earthquakes. These show greater dispersion as strain rate increases because the size of the areas in which these strain rate levels occur decreases. The spread for a random distribution is shown as grey vertical error bars on the coloured points. The solid black line shows the linear best fit, and the two dashed lines show the $1 \sigma$ errors on the line, assuming that earthquakes are a Poisson process. The curved grey line shows the best power-law fit, with an exponent of 1.42. (b) G-R plot of declustered 10- and 100-yr catalogue within areas of different strain rate, normalized per area.

We test the impact of our binning, $1 \times 10^{-8} \mathrm{yr}^{-1}$, by analysing the results of $0.5 \times 10^{-8}$ and $0.1 \times 10^{-8} \mathrm{yr}^{-1}$. A similar correlation between density of earthquake rate and strain rate can be seen using any bin width, though the scatter increases as bin width decreases (see Fig. S4). G-R plots of these two smaller bin widths again both show the correlation between density of earthquake rate and strain rate (Fig. S5). We also find that our calculated $M_{\mathrm{c}}$ value is not critical to the correlation, since using $M_{\mathrm{c}}=4.5$ gives an almost identical trend (Fig. S6).

The seismicity rate produced in a particular area thus seems to be proportional, to first-order, to the strain rate. So H3 (the rate of earthquake nucleation is proportional to the stress rate) seems verified in our study area, although the data suggest that the relationship might actually be non-linear. We therefore consider the two alternative hypotheses.

\section{$6.1 a$ - and $b$-values}

If we know the density of earthquake rate $M_{\mathrm{w}} \geq 4, \dot{N}$, and we know the $b$-value, we can then work out the $a$-value, $\operatorname{since} \log _{10}(\dot{N})=a-M_{\mathrm{w}} \cdot b$. Eqs (3) and (4) show two different cases for how $\dot{N}$ could be related to $\dot{\epsilon}$, and here we show the $a$-value for both of these cases, which we call Case 1 (linear) and Case 2 (power law).

Case 1: eqs (1) and (3) imply

$a_{\mathrm{pa}}=\log _{10}(\lambda \cdot \dot{\epsilon})+b \cdot M_{\mathrm{c}}$

where $a_{\mathrm{pa}}$ is the $a$-value per unit area, and has units $\mathrm{m}^{-2} \mathrm{yr}^{-1} \cdot \lambda$ is the same constant as in eq. (3) and here $M_{\mathrm{c}}=4$.

Case 2: eqs (1) and (4) imply

$a_{\mathrm{pa}}=\log _{10}\left(\gamma_{1} \cdot \dot{\epsilon}^{\gamma_{2}}\right)+b \cdot M_{\mathrm{c}}$

where $\gamma_{1}$ and $\gamma_{2}$ are the constants from eq. (4).

We determine $b$-values using the maximum likelihood method (Aki 1965; Utsu 1965) using the correction of Bender (1983), and we use the equation of Shi \& Bolt (1982) to estimate the error, as suggested by Marzocchi \& Sandri (2003) to get unbiased results:

$b=\frac{1}{\ln (10)\left[\hat{\mu}-\left(M_{\text {thresh }}-\Delta M / 2\right)\right]}$

$\sigma_{b}=\frac{b}{\sqrt{n}}$,

where $\hat{\mu}$ is the average magnitude of earthquakes above the cut-off magnitude, $M_{\text {thresh }}$ is the cut-off magnitude, $\Delta M$ is the width of the magnitude bins, here 0.1 and $n$ is the number of earthquakes above the cut-off magnitude. 
Table 1. Seismicity characteristics of areas of different strain rate, derived from 10-yr catalogue. $a_{\mathrm{pa}}$ has units of $\mathrm{m}^{-2} \mathrm{yr}^{-1}$ and is found from $\log _{10}\left(\dot{N}\left(M_{\mathrm{w}}>M / \mathrm{m}^{2}\right)\right)$, where $\dot{N}$ is the density of earthquakes per year, and is the $y$-axis intercept, which can be thought of as the earthquake productivity. $b$ is the slope of the line and relates the number of smaller to larger earthquakes, and is the value found from $\mathrm{G}-\mathrm{R}$ maximum likelihood for the entire area. $M_{\max }$ and $T_{\mathrm{r}}$ are shown for Case 1 (linear), and Case 2 (non-linear). Lower $M_{\max }$ values assume $c_{\mathrm{g}}=2$ while upper $M_{\max }$ values assume $c_{\mathrm{g}}=4$.

\begin{tabular}{lccccccccccc}
\hline $\begin{array}{l}\text { Strain rate } \\
10^{-8} \mathrm{yr}^{-1}\end{array}$ & $\begin{array}{c}\text { Area } \\
10^{3} \mathrm{~km}^{2}\end{array}$ & $\begin{array}{c}N_{\text {eqs }} \\
M_{\mathrm{w}} \geq 4\end{array}$ & $\begin{array}{c}N_{\text {eqs }} / \text { area } \\
M_{\mathrm{w}} \geq 4\end{array}$ & $b$ & $\sigma_{b}$ & \multicolumn{4}{c}{ Case 1} & \multicolumn{2}{c}{ Case 2 } \\
\hline $0-1$ & 4984 & 725 & 0.145 & 1.06 & 0.01 & -6.7 & $8.7-9.4$ & $1500-8050$ & -7.1 & $9.8-10.5$ & $70000-370000$ \\
$1-2$ & 5357 & 1444 & 0.270 & 1.06 & 0.01 & -6.2 & $8.7-9.4$ & $470-2500$ & -6.5 & $9.3-10.0$ & $4440-23600$ \\
$2-3$ & 2685 & 1761 & 0.656 & 1.06 & 0.01 & -6.0 & $8.7-9.4$ & $562-3000$ & -6.2 & $9.1-9.8$ & $2550-13575$ \\
$3-4$ & 1598 & 1349 & 0.844 & 1.06 & 0.01 & -5.8 & $8.7-9.4$ & $675-3600$ & -5.9 & $9.0-9.7$ & $1900-10050$ \\
$4-5$ & 905 & 765 & 0.846 & 1.06 & 0.01 & -5.7 & $8.7-9.4$ & $925-5000$ & -5.8 & $8.9-9.6$ & $1800-9650$ \\
$5-6$ & 681 & 689 & 1.012 & 1.06 & 0.01 & -5.6 & $8.7-9.4$ & $1000-5350$ & -5.7 & $8.8-9.5$ & $1480-7870$ \\
$6-7$ & 324 & 410 & 1.267 & 1.06 & 0.01 & -5.5 & $8.7-9.4$ & $1790-9530$ & -5.6 & $8.7-9.4$ & $2070-11000$ \\
$7-8$ & 208 & 411 & 1.972 & 1.06 & 0.01 & -5.5 & $8.7-9.4$ & $2420-12800$ & -5.5 & $8.7-9.4$ & $2280-12200$ \\
$8-9$ & 165 & 385 & 2.332 & 1.06 & 0.01 & -5.4 & $8.7-9.4$ & $2700-14300$ & -5.4 & $8.6-9.3$ & $2120-11260$ \\
$9+$ & 185 & 505 & 2.728 & 1.06 & 0.01 & -5.4 & $8.7-9.4$ & $2150-11400$ & -5.3 & $8.6-9.3$ & $1440-76600$ \\
Combined & 17092 & 8444 & 0.494 & 1.06 & 0.01 & & & & & & \\
\hline
\end{tabular}

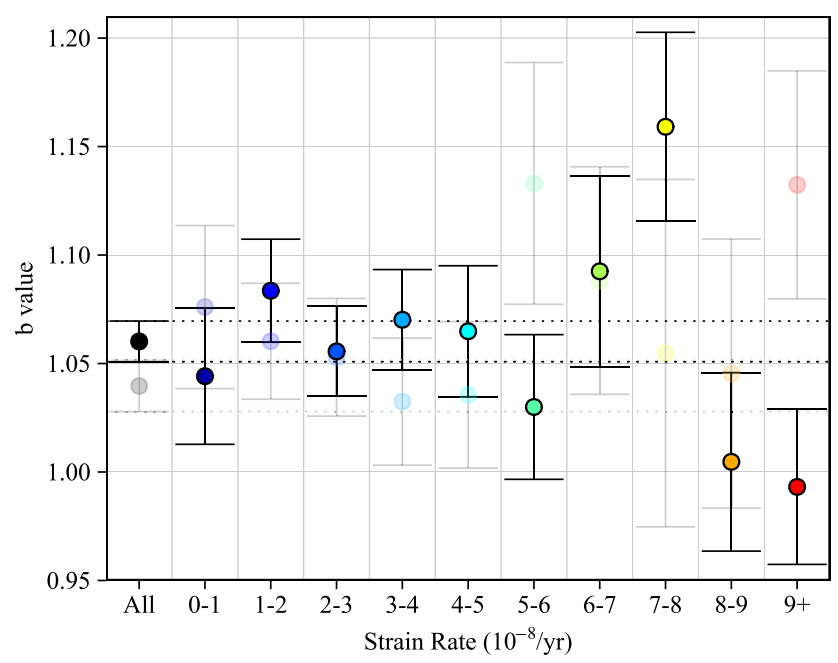

Figure 11. $b$-Values found for the entire area (All), and for the different strain rate areas from the 10-yr instrumental catalogue. The values from the previous $10 \mathrm{yr}(2000-2010)$ are shown faded in the background.

Here we assume a minimum cut-off value of $M_{\mathrm{w}} 4$ for all areas. We find that in the areas of higher strain where there are fewer earthquakes (Table 1), the errors on the $b$-value are larger (Fig. 11). We don't see any trend that would suggest a dependency of the $b$-value on strain rate. We also see that if we calculate $b$ values using the previous $10 \mathrm{yr}$ of instrumental data (2000-2010), the areas of higher strain show the largest variability. Because of this large variability, we assume that the $b$-value for the entire region, $1.06 \pm 0.01$, is valid in all areas. In general, the 100 -yr catalogue is fit well by this constant $b$ - and the $a_{\mathrm{pa}}$-values found from the 10 -yr catalogue, apart from the lowest strain rate area where there are fewer earthquakes in the historical catalogue than we would expect.

To test the impact of binning, we again study the results from bin widths $0.5 \times 10^{-8}$ and $0.1 \times 10^{-8} \mathrm{yr}^{-1}$ (Fig. S7). For a bin width of $0.5 \times 10^{-8} \mathrm{yr}^{-1}$, the $b$ - values fall mainly within the error bars of the original bin width, $1 \times 10^{-8} \mathrm{yr}^{-1}$. For a bin width of $0.1 \times 10^{-8} \mathrm{yr}^{-1}$, too few earthquakes occur within each bin, and the $b$-values are more scattered. In neither case do we see a dependency of $b$-values on strain rate.

\subsection{Moment conservation and $M_{\max }$}

The moment conservation principle applies to the moment tensor as a whole. However, we simply retain a scalar form and use the second invariant, $\dot{\epsilon}$, which reflects the magnitude of the total strain rate:

$\dot{\epsilon}=\sqrt{\dot{\epsilon}_{\mathrm{NN}}^{2}+\dot{\epsilon}_{\mathrm{EE}}^{2}+2 \dot{\epsilon}_{\mathrm{NE}}^{2}}$.

Then to calculate the moment buildup rate, $\dot{m}$, in the different strain rate regions, we use

$\dot{m}=c_{\mathrm{g}} \cdot \mu \cdot T_{\mathrm{s}} \cdot A \cdot \dot{\epsilon}$, 
where $\mu$ is the rigidity, here assumed to be $33 \mathrm{GPa}, A$ is the area of the strain rate zone, $T_{s}$ is the seismogenic thickness, here assumed to be $15 \mathrm{~km}$ (e.g. Elliott et al. 2010; Wei et al. 2010) and $c_{\mathrm{g}}$ is a geometric factor. The value of $c_{\mathrm{g}}$ depends on the orientation and dip angle, $\delta$, of the faults taking up the strain. For dip-slip faults with uniaxial compression, $c_{\mathrm{g}}=1 /[\sin (\delta) \cdot \cos (\delta)]$, which takes into account the increased area of fault plane per unit length, and the partitioning of the horizontal strain rate onto the fault plane. For dip-slip faults of $45-15^{\circ}$ dip, $c_{\mathrm{g}}$ varies $2-4$. For a conjugate set of vertical strike-slip faults striking $\alpha$ to the direction of principal strain, $c_{\mathrm{g}}=\sqrt{2} /[\sin (\alpha) \cdot \cos (\alpha)]$, where $\sqrt{2}$ comes from the bi-axial nature of the strain rate, and definition of the second invariant. If $\alpha=30^{\circ}, c_{\mathrm{g}}=3.3$. We consider two end-member possibilities, one with $c_{\mathrm{g}}=2$ and one with $c_{\mathrm{g}}=4$, to find both the minimum moment buildup, and to account for the low-angle thrust faults in this region, such as the Main Himalayan Trust, which has a dip of $\sim 15^{\circ}$ (e.g. Elliott et al. 2016).

We then use moment conservation to balance the moment buildup rate with the moment release rate from earthquakes, and assuming that earthquakes follow a truncated G-R distribution, to find $M_{\max }$. We rearrange eq. (5) of Avouac (2015), which expresses moment conservation for a truncated G-R seismicity model, as in eq. (1), substituting $\log _{10}\left(N_{\max }\right)=a-b \cdot M_{\max }$, to get:

$M_{\max }=\frac{1}{3 / 2-b}\left(\log _{10}\left(1-\frac{2 \cdot b}{3}\right)+\log _{10}(\alpha \cdot \dot{m})-9-a\right)$,

where $a$ and $b$ are $\mathrm{G}-\mathrm{R}$ parameters, $\alpha$ is the fraction of moment that is released seismically, here assumed to be 1 , and $\dot{m}$ is the moment buildup rate. We see that the parameters controlling $M_{\max }$ are $a, b$ and $\dot{m}$. We can now substitute the $\dot{m}$-value from eq. (10) and the $a$-value for the entire strain rate regions into eq. (11) for $M_{\max }$, for both Case 1 and Case 2. Case 1: the $a$-value for the entire region is

$a=\log _{10}(\lambda \cdot \dot{\epsilon} \cdot A)+4 \cdot b$,

where $a$ is $\mathrm{yr}^{-1}$, for the entire strain rate region, of area $A$. We substitute this $a$-value into eq. (11) for $M_{\max }$ :

$M_{\max }=\frac{1}{3 / 2-b}\left[\log _{10}\left(1-\frac{2 \cdot b}{3}\right)+\log _{10}\left(\alpha \cdot c_{\mathrm{g}} \cdot \mu \cdot T_{\mathrm{s}} \cdot A \cdot \dot{\epsilon}\right)-9-\log _{10}(\lambda \cdot \dot{\epsilon} \cdot A)-4 \cdot b\right]$.

We see that the strain rate, $\dot{\epsilon}$, and area, $A$, terms cancel out leaving us with

$M_{\max }=\frac{1}{3 / 2-b}\left[\log _{10}\left(1-\frac{2 \cdot b}{3}\right)+\log _{10}\left(\alpha \cdot c_{\mathrm{g}} \cdot \mu \cdot T_{\mathrm{s}}\right)-9-\log _{10}(\lambda)-4 \cdot b\right]$.

In this case, $M_{\max }$ is independent of both strain rate and area. This is because an increase in area and strain rate not only increases the moment buildup rate, but also increases the number of earthquakes, that is the $a$-values, so to conserve moment, the same $M_{\text {max }}$ would be needed. In other words, areas of higher strain rate have more earthquakes to 'compensate' for the higher strain rate, so $M_{\max }$ does not need to increase. If the density of earthquake rate, $\dot{N}$ and so $a_{\mathrm{pa}}$, were the same in all areas, the higher strain rate areas would then need higher $M_{\text {max }}$.

Case 2: The $a$-value for the entire strain rate regions is now

$a=\log _{10}\left(\gamma_{1} \cdot \dot{\epsilon}^{\gamma_{2}} \cdot A\right)+4 \cdot b$.

Therefore

$M_{\max }=\frac{1}{3 / 2-b}\left[\log _{10}\left(1-\frac{2 \cdot b}{3}\right)+\log _{10}\left(\alpha \cdot c_{\mathrm{g}} \cdot \mu \cdot T_{\mathrm{s}} \cdot A \cdot \dot{\epsilon}\right)-9-\log _{10}\left(\gamma_{1} \cdot \dot{\epsilon}^{\gamma_{2}} \cdot A\right)-4 \cdot b\right]$.

We see that the area term, $A$, cancels out, but now strain rate, $\dot{\epsilon}$, remains in the equation:

$M_{\max }=\frac{1}{3 / 2-b}\left[\log _{10}\left(1-\frac{2 \cdot b}{3}\right)+\log _{10}\left(\alpha \cdot c_{\mathrm{g}} \cdot \mu \cdot T_{\mathrm{s}}\right)-9-\log _{10}\left(\gamma_{1}\right)+\log _{10}\left(\dot{\epsilon}^{1-\gamma_{2}}\right)-4 \cdot b\right]$.

So for Case 2, where $\dot{N}$ is non-linear with respect to $\dot{\epsilon}, M_{\max }$ decreases as $\dot{\epsilon}$ increases (since $\gamma_{2}>1$, here $\gamma_{2}=1.42$ ). While this may be slightly surprising, large earthquakes are seen in areas of very low $\dot{\epsilon}$ (e.g., Crone et al. 2003; Walker et al. 2015; Calais et al. 2016), and the return time of these earthquakes in rate areas is still expected to be longer than those in higher strain rate areas. It may also be that there is correlation between the strain rate and the fraction of moment released seismically, or the dip of the faults, so if in areas of lower strain a lower proportion of moment was released seismically, or the faults where steeper dipping, then the calculated $M_{\max }$ in these regions would decrease.

The recurrence time of $M_{\max }$ is then

$T_{\mathrm{r}}=1 /\left(10^{a-b \cdot M_{\max }}\right)$,

where $a$ is the $a$-value for the entire strain rate region, as in eqs (12) and (15). So unlike $M_{\max }, T_{\mathrm{r}}\left(M_{\max }\right)$ does depend on both $\dot{\epsilon}$ and $A$. An increase in either $\dot{\epsilon}$ or $A$ will lead to a shorter $T_{\mathrm{r}}\left(M_{\max }\right)$. Table 1 lists $M_{\max }$ and $T_{\mathrm{r}}\left(M_{\max }\right)$ for Cases 1 and 2.

Apart from $b$, other variables that can change are $T_{\mathrm{s}}$ and $\alpha$, which contribute to the moment buildup rate, and $\lambda$, or $\gamma_{1}$ and $\gamma_{2}$, which are the coefficients relating the density of earthquake rate and the strain rate. Roughly speaking, if $T_{\mathrm{s}}$ or $\alpha$ are halved, $M_{\max }$ will decrease by about 0.6 units of magnitude. If $\lambda$ is halved (i.e. rate of earthquakes in each region of strain rate is halved), then $M_{\max }$ will increase by about 0.6 units of magnitude.

One simplification we made was from finding the moment buildup from the strain rate, eq. (10). We chose the values of $c_{g}$ to be a reasonable guess independent of tectonic regime. In areas where there are fewer low-angle faults, the resulting moment rate calculated will 


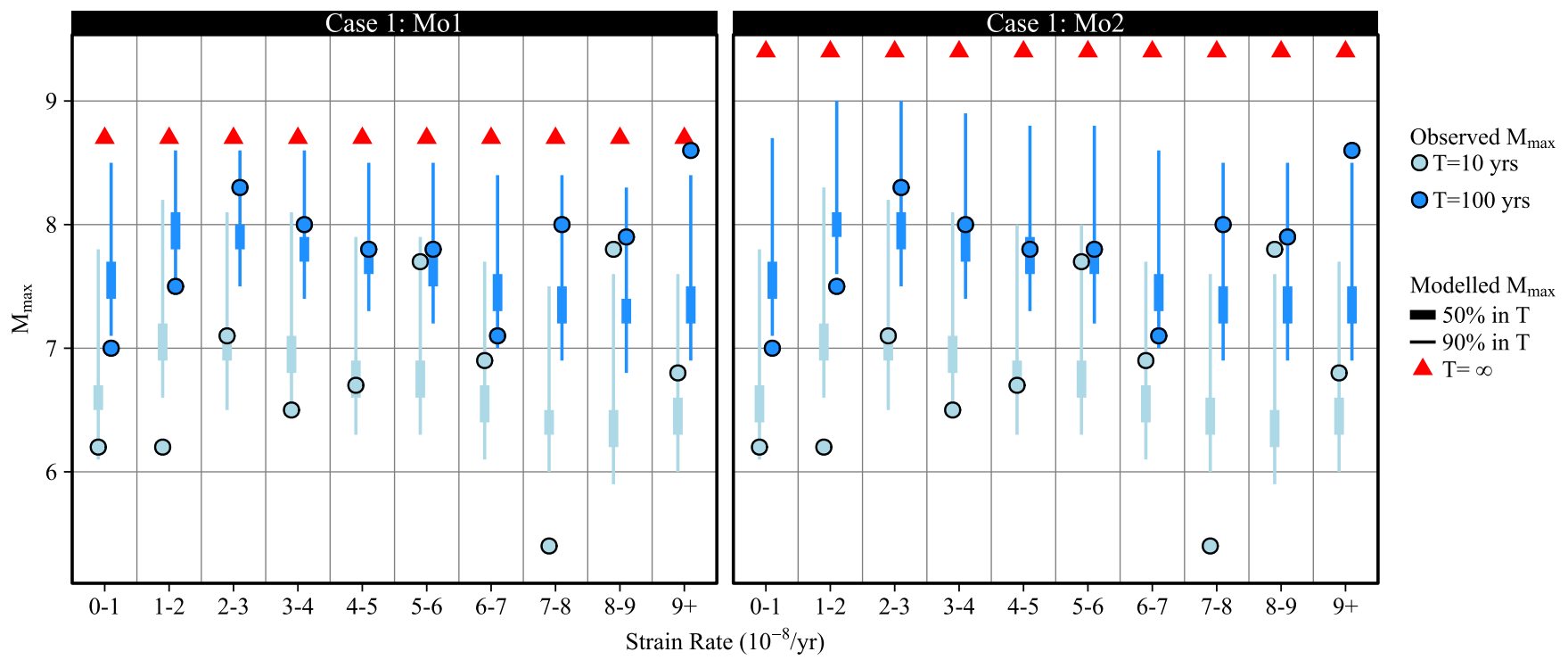

Figure 12. Comparison of the largest magnitudes observed in the 10- and 100-yr catalogues with the synthetic catalogues generated with our model Case 1. The red triangles show the absolute $M_{\max }$ expected in the model, and the blue lines show given the model, the probable $M_{\max }$ seen within the different time periods. The thick lines show the 25 th- 75 th quantile of the probability distribution, and the thin lines show the 5 th- 95th quantile, meaning that if the model is correct, there is a 10 per cent chance that the observations do not fall on the thin lines. Cases are shown for a moment buildup of Mo1, where $c_{\mathrm{g}}=2$, and Mo2, where $c_{\mathrm{g}}=4$.
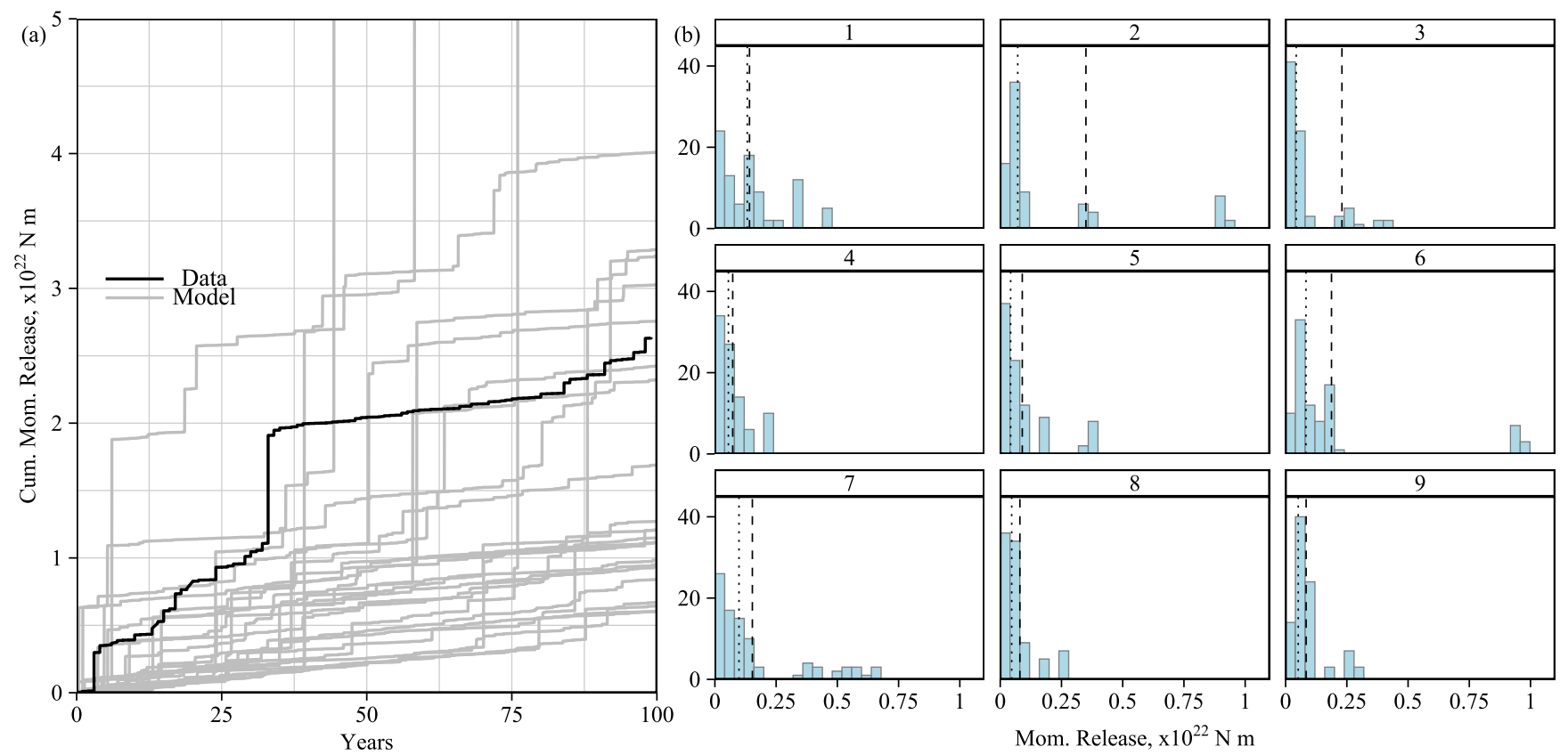

Figure 13. Moment release from modelled catalogues. (a) 25 modelled catalogues showing cumulative moment release over a period of $100 \mathrm{yr}$, with the real moment release from 1916 to 2016 shown in black (see Fig. 1b). (b) Nine example catalogues showing moment release binned in different 10-yr periods. Dashed and dotted line show mean and median moment release of 10 -yr periods, respectively.

be an overestimation. We have also assumed that $\alpha=1$, which could also lead to an overestimation of moment rate. In areas of lower strain, for Case 2, we see that we estimate unreasonable large $M_{\max }$ (Table 1). In these areas we steeper dipping faults, or more moment released aseismically, would lead to a decrease in $M_{\max }$.

To test our model, we compare expected and observed largest magnitude earthquakes in the different areas over 10 and $100 \mathrm{yr}$, and the modelled versus observed overall moment release distribution for the past $100 \mathrm{yr}$ (Figs 12 and 13). We simulate 10 000-, 10- and 100-yr catalogues drawn from our modelled distribution. For each catalogue, we determine the maximum event in each strain rate bin and get a distribution that we compare to observed maximum magnitudes in the 10- and 100-yr catalogues. We plot the 25th-75th quantile (thick blue lines) and 5th-95th quantile (thin blue lines) of the distribution obtained from the synthetic catalogues, along with the absolute $M_{\text {max }}$ of our model (red triangles) for each strain rate bin. All magnitudes are rounded to the first decimal. In all cases, even for the 100 -yr periods, there is 
less than a 5 per cent chance that the largest earthquake we observe would have a magnitude equal to absolute $M_{\max }$, given the rounding to the first decimal: This is shown by the distance between the thin blue lines and the red triangles. The largest magnitude earthquakes observed are plotted as blue circles. In general, these are consistent with our modelled seismicity, since most observations fall on the blue lines (there is a 10 per cent chance that if our model is correct, the observed values would not fall on the blue lines). For the strain rate area $7-8 \times 10^{-8} \mathrm{yr}^{-1}$, in the 10-yr catalogue, $M_{\max }$ observed is less than 6 , which our model suggests has a low, $<5$ per cent, probability of occurrence. For the 100 -yr catalogues for the same strain rate bin, the observed maximum magnitude is very similar to the expected maximum value predicted by our model.

We note that the model predicts an overall $M_{\max }=8.7-9.4$ depending on the geometry of faults that take up the strain, that is the $c_{\mathrm{g}}$ value we use. According to the historical catalogue, there have been two earthquakes of $M_{\mathrm{w}}>8$ over the last $100 \mathrm{yr}$ (the $M_{\mathrm{w}} 8.31920$ Haiyuan earthquake in northeastern Tibet and the $M_{\mathrm{w}} \sim 8.61950$ Assam earthquake of northern India), but no earthquakes $M_{\mathrm{w}} \geq 9$. However, local application of moment conservation on the low-angle Main Himalayan Thrust Fault requires a $M_{\max } \sim 9.0$ (Stevens \& Avouac 2016). This estimate is consistent with the $M_{\mathrm{w}} 8.6$ magnitude of the great Assam earthquake (Chen \& Molnar 1977) and palaeoseismic evidence for $M_{\mathrm{w}}$ $\geq 8.5$ earthquakes (e.g. Lavé et al. 2005; Kumar et al. 2006, 2010; Bollinger et al. 2014).

The observed distribution of moment release from 1906 to 2016, and 25 realizations of our modelled catalogue, are shown in Fig. 13. We also show examples from nine modelled catalogues of binning the moment release into different 10-yr periods, which can be compared to the real data shown in Fig. 1(c). We see that our synthetic catalogues reproduce well the variability of moment release seen in the data.

\section{DISCUSSION}

\subsection{Relationships between strain rate, seismicity rate and $M_{\max }$}

Our study shows that geodetic rates govern spatial variations of earthquake rates over the India-Asia collision zone. Such a result is expected if earthquakes are triggered by interseismic loading and if the geodetic data have sufficient resolution to capture the spatial variations of the stress tensor. It is consistent with the positive correlation reported by Kreemer et al. (2002), Kagan (1997) and Shen et al. (2007) at the global scale, for subduction zones in particular, and at the regional scale for Southern California respectively. Although it is intuitive that seismicity might correlate with strain rate, one could also imagine $M_{\max }$ or the $b$-value characterizing the magnitude-frequency distribution of earthquakes varying with strain rate. Our analysis actually quantifies how spatial variations of seismicity rate, $M_{\max }$ and $b$-values are linked by virtue of the moment conservation principle.

We find that the $b$-value is insensitive to the strain rate and that the correlation between earthquake rate is linear to first order. This linear correlation in space is the equivalent in space of correlation in time between post-seismic strain rates and aftershocks (e.g. Perfettini \& Avouac 2004a; Hsu et al. 2006). The fact that, according to our study, the correlation holds in areas of lower strain rates suggests that, even in those areas, geodetic strain is probably dominantly elastic and released by seismicity in the longer run. If this were not the case, we would expect a cut-off strain rate below which we would get no seismicity, corresponding to maximum strain rate that can be absorbed by viscous deformation. We do not see such a cut-off in our data.

The expected maximum event to be observed in an area $A$, of strain rate $\dot{\epsilon}$, in a period of duration $T$, is a function of only the cumulative strain, $T \cdot \dot{\epsilon}$. Combining the G-R law with our values calculated for $a$ (eq. (12) for Case 1 or eq. (15) for Case 2), we see that:

$M_{\mathrm{exp}}^{1}(T)=\frac{\log _{10}(\lambda \cdot \dot{\epsilon} \cdot T \cdot A)}{b}+M_{\mathrm{c}}$

and

$M_{\mathrm{exp}}^{2}(T)=\frac{\log _{10}\left(\gamma_{1} \cdot \dot{\epsilon}^{\gamma_{2}} \cdot T \cdot A\right)}{b}+M_{\mathrm{c}}$

where $M_{\exp }^{1}(T)$ and $M_{\exp }^{2}(T)$ are the expected value of the largest magnitude earthquake in time $T$ for Case 1 and Case 2 , respectively. We show the results from this equation together with the observed largest earthquakes in 10 and 100 yr in Table 2.

Our data suggest that the relationship between seismicity rate and strain rate might actually be non-linear. A power-law relationship, with $\dot{N}$ proportional to $\dot{\epsilon}^{1.42}$ indeed yields a slightly better fit to the data. The possibility for a non-linear relationship between seismicity rate and strain rate suggested by Fig. 10 is reminiscent of the finding by Bird (2009) of a non-linear relationship between seismicity rate and slip rate at continental convergent boundaries (CCB). CCB are defined in their study as zones of continental convergence with a Benioff zone of intermediate to deep earthquakes and/or a parallel volcanic arc with Quaternary activity. This definition actually excludes most orogens in general, and our study area in particular. It includes less complicated zones of continental deformation along segments of plate boundaries with convergence rate spanning $<10$ to $>80 \mathrm{~mm} \mathrm{yr}^{-1}$, with a mean value of $24 \mathrm{~mm} \mathrm{yr}^{-1}$. Slip rates on individual faults in the India-Asia collision zones fall in the lower range covered by the CCB class of Bird (2009). So although our observation was obtained following a different procedure, it seems to confirm a non-linear behaviour for zones of continental convergence not included in the previous study of Bird (2009), and with lower deformation rates. It is interesting to note that Bird (2009) did, however, find a linear correlation for continental transform faults and continental rift zones. Our study area includes a mix of thrust, strike-slip and normal faults. It could be that the non-linear behaviour is a specific characteristic of thrust tectonics. If we analyse separately areas of negative first invariant of strain rate, that is, areas of 
Table 2. The largest earthquakes observed $\left(M_{\mathrm{obs}}\right)$, and those expected for Case 1 $\left(M_{\mathrm{exp}}^{1}\right)$ and Case $2\left(M_{\exp }^{2}\right)$, in the 10- and 100-yr time periods, for the different strain rate bins. The expected values are calculated from eqs (19) and (20).

\begin{tabular}{lcccccc}
\hline $\begin{array}{l}\text { Strain rate } \\
10^{-8} \mathrm{yr}^{-1}\end{array}$ & $M_{\text {obs }}$ & $\begin{array}{c}10 \mathrm{yr} \\
M_{\exp }^{1}\end{array}$ & $M_{\exp }^{2}$ & $M_{\text {obs }}$ & $\begin{array}{c}100 \mathrm{yr} \\
M_{\exp }^{1}\end{array}$ & $M_{\exp }^{2}$ \\
\hline $0-1$ & 6.2 & 6.6 & 6.2 & 7.0 & 7.6 & 7.1 \\
$1-2$ & 6.2 & 7.1 & 6.8 & 7.5 & 8.1 & 7.8 \\
$2-3$ & 7.1 & 7.0 & 6.9 & 8.3 & 8.0 & 7.8 \\
$3-4$ & 6.5 & 7.0 & 6.8 & 8.0 & 7.9 & 7.8 \\
$4-5$ & 6.7 & 6.8 & 6.8 & 7.8 & 7.8 & 7.7 \\
$5-6$ & 7.7 & 6.8 & 6.8 & 7.8 & 7.7 & 7.7 \\
$6-7$ & 6.9 & 6.6 & 6.5 & 7.1 & 7.5 & 7.5 \\
$7-8$ & 5.4 & 6.4 & 6.5 & 8.0 & 7.4 & 7.4 \\
$8-9$ & 7.8 & 6.4 & 6.4 & 7.9 & 7.3 & 7.4 \\
$9+$ & 6.8 & 6.5 & 6.5 & 8.6 & 7.4 & 7.5 \\
\hline
\end{tabular}

thrust tectonics, we do indeed see a hint that the non-linear behaviour is enhanced in these regions (Fig. S8). The data set is too small for a conclusive test restricted to the earthquakes in strike-slip and normal faulting areas.

A non-linear relationship would be expected if a fraction of interseismic strain is absorbed by non-linear viscous deformation. The implications of the possible non-linear relationship between seismicity rate and strain rate for the rheology of the lithosphere and earthquake physics are beyond the scope of this study, however it is interesting to note that a power-law relationship implies that $M_{\text {max }}$ depends on the strain rate according to eq. (17). Given that the power-law exponent is larger than unity we find that $M_{\max }$ should be anticorrelated with the strain rate. This result is counter-intuitive but it is worth pointing out that it could be qualitatively consistent with the finding of Riguzzi et al. (2012) for Italy that larger earthquakes tend to occur in areas of lower strain rate.

As a refinement to the model, it would be possible to introduce a local, rather than global moment budget for the strain rate zone, for example by accounting for spatial variations of the tectonic regime, and hence of fault dip angles. Regions of shallow dip-angle thrusting, like the Himalaya, would then have larger $M_{\max }$ than regions of strike-slip faulting like most of Tibet. This would make the method more consistent with local studies based on the moment budget and interseismic coupling models, such as Stevens \& Avouac (2016) for the Main Himalayan Thrust or Rollins \& Avouac (2019) for the Los Angeles Basin.

\subsection{Relationship between strain tensor and earthquake moment tensor}

The approximate proportionality of the geodetic strain rate tensor and moment tensors suggests that the strain rate tensor has not changed much through time. This means that the current strain rates measured over decades can be extrapolated back in time to evaluate strain build-up on active faults over the entire interseismic period. This lends support to the practice of combining geological slip rates and seismicity data to develop kinematic models of continental deformation (Haines \& Holt 1993; Holt et al. 1995; England \& Molnar 1997) or elastic block modelling (e.g. Meade \& Hager 2005). There are, however, more heterogeneities in the orientation of the focal mechanisms than what would be expected from the geodetic strain field. This observation calls for sources of stress heterogeneities other than interseismic strain. Stress heterogeneities could result, for example, from topographic stresses, heterogeneities of elastic properties and variations of fault friction (Rivera \& Kanamori 2002; Bollinger et al. 2004; Fialko et al. 2005). Earthquakes themselves change the stress-field locally and must cause time-dependent heterogeneities of stresses (e.g. Hardebeck \& Hauksson 2001). Erosion of the topography can additionally cause non-negligible variations of the stress field (Steer et al. 2014). Assessing the contribution of these effects to the observed misfit is not straightforward however.

Over larger spatial scales, the correlation between seismic and geodetic tensors should improve. Previous studies have indeed shown that the scatter in the moment tensor does average out to match the geodetic strain tensor at some scale (Amelung \& King 1997; Shen-Tu et al. 1998; Kreemer et al. 2002; Masson et al. 2005). We used GPS from the literature that had been correction for large seismic events, however our 'interseismic' strain includes the coseismic strain due to some smaller, $M<7$ earthquakes. In the historical catalogue, earthquakes $M<7$ have release only $\sim 10$ per cent of the total moment, so we can assume that the correlation between geodetic strain and seismicity is not due to geodetic strain being coseismic.

\subsection{The problem of the low strain rate areas}

The approach described here to infer seismicity from geodetic strain rate seems effective for areas with relatively large strain rates ( $\geq 2 \times$ $\left.10^{-8} \mathrm{yr}^{-1}\right)$. It is not clear, however, that geodetic strain rates provide good guidance to define zones of homogeneous seismicity rate in areas with lower strain rate. It is interesting in that regard to contrast the India-Asia collision zone area with other areas where limited correlation between strain rates and directions and seismicity is observed. This is, for example, the case in Fennoscandia (Bungum et al. 2010; Keiding et al. 2015; Craig et al. 2016) and the New Madrid seismic zone of the central United States (Newman et al. 1999). In Fennoscandia, the current seismicity is probably releasing elastic strain accumulated as a result of postglacial relaxation in addition to the strain that has 


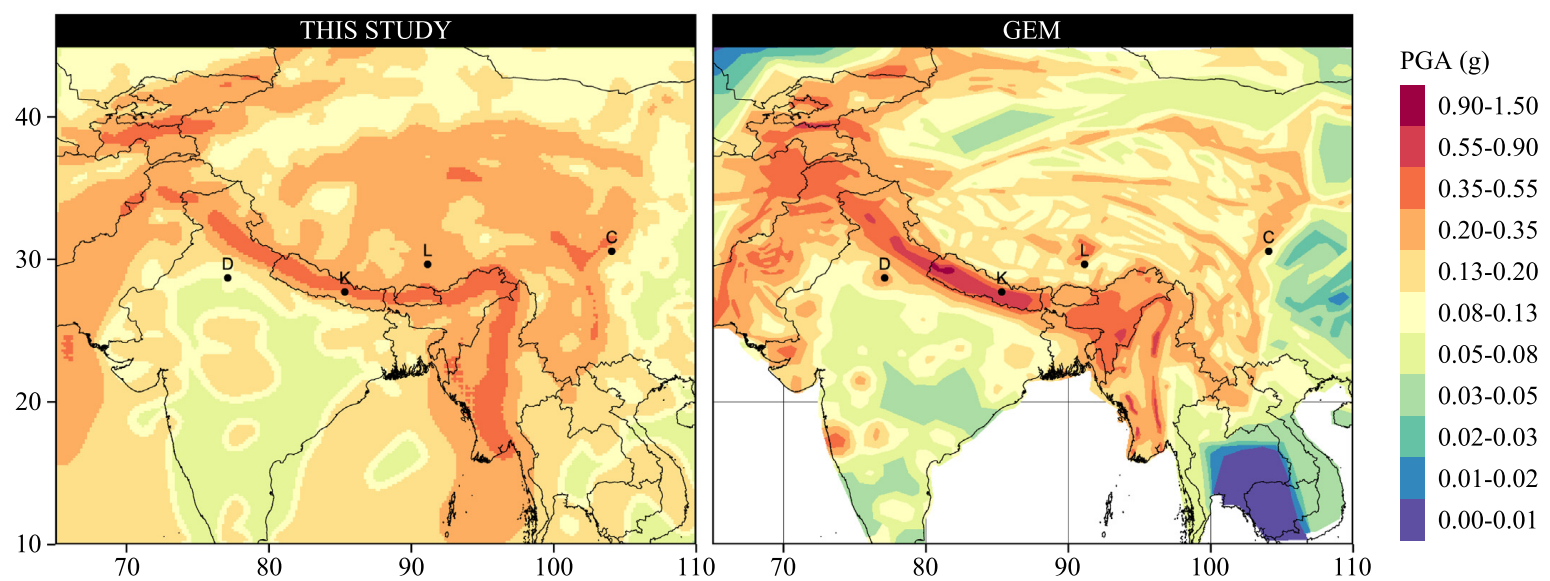

Figure 14. Comparison of PGA (g) with 10 per cent chance in $50 \mathrm{yr}$ between this study and GEM (Nath \& Thingbaijam 2012; Anon. 2015; Pagani et al. 2018), both for a reference Vs30 of $780 \mathrm{~m} \mathrm{~s}^{-1}$. D = Delhi, $\mathrm{K}=\mathrm{Kathmandu}, \mathrm{L}=$ Lhasa, $\mathrm{C}=$ Chengdu. Hazard curves for these four locations are shown in Fig. 16. Our seismic hazard model including site conditions is shown in Fig. S9.

accumulated as a result of on-going tectonics (Bungum et al. 2010; Keiding et al. 2015). So the modern geodetic strain rate tensor might not be collinear with the accumulated elastic strain available to be released by earthquakes.

In the New Madrid seismic zone, postglacial rebound could also play a role, although it has been suggested that the large earthquakes have been caused by stress changes due to erosion, sedimentation and subsequent flexure of the lithosphere (Calais et al. 2010). It is probable that in low strain areas, tectonic loading has not overprinted elastic strain dues to non-stationary processes such as postglacial rebound, erosion or sedimentation. In addition, it seems that in stable areas large earthquakes are clustered in time and space so that the assumption of a Poisson process with uniform probability is a most questionable hypothesis (e.g. Liu \& Stein 2016; Salditch et al. 2020).

\subsection{From geodetic strain rates to probabilistic seismic hazard analysis}

We have shown in previous sections that seismicity in our study area is closely related to geodetic strain rate, in terms of principal strain rate directions and rate of earthquakes. Therefore the strain rate from the GPS can be combined with the instrumental seismicity to produce probabilistic seismicity models using a relatively simple procedure. These seismicity models can then be used as an input to probabilistic seismic hazard analysis as we illustrate here.

We use OpenQuake (Pagani et al. 2014) to perform an area-based probabilistic seismic hazard analysis. Because all four seismicity models presented above may be adequate to use as an input, we use the $a, b$ and $M_{\max }$ parameters found using the linear and non-linear models, and two different values of moment build-up rate (see Table 1). Some weighting scheme then needs to be adopted to consider them jointly. We estimate their relative probabilities by comparing them to the 100-yr catalogue. We first compare the number of earthquakes $M_{\mathrm{w}}$ $\geq 6$ (the magnitude of completeness) in the data in each different strain bin, with the number expected for Case 1 and Case 2. We find that Case 2 fits the data with a probability 1.2 times that of Case 1. We then look at the maximum magnitude earthquakes in each different strain bin. None of our values for $M_{\max }$ have been exceeded in any strain rate bin, and the largest earthquake we expect to see in 100 yr differs very little considering our different $M_{\max }$ values, since the expected return times of the largest earthquakes are much longer than a 100-yr period. We therefore consider either value for moment buildup, and therefore $M_{\max }$, equally likely. This gives us weights for Case1 Mo1: Case1 Mo2 : Case2 Mo1 : Case2 Mo2 of 1: 1: 1.2: 1.2.

We characterize the hazard by peak ground acceleration (PGA) with 10 per cent chance in $50 \mathrm{yr}$, using three different ground motion prediction equations (GMPEs), selected from the default recommendations of GEM for both active crust and subduction zones (Boore et al. 2014; Chiou \& Youngs 2014; Zhao et al. 2006), to account for path effects. We calculate the PGA for a reference Vs30 (the estimated average $S$-wave velocity over the shallower $30 \mathrm{~m}$ ) of $780 \mathrm{~m} \mathrm{~s}^{-1}$ (Fig. 14a), and also show the results using proxy Vs30 values calculated by the UGSS (Allen \& Wald 2009) in the Supporting Information (Fig. S9). Our hazard maps looks very similar to our strain rate map (Fig. 2b) since the areas are defined based on the strain rate, and the areas of higher strain have larger $a$-values, which leads to a higher hazard.

We show how the four individual models differ from the average in Fig. 15. For Case 1, the linear models, the regions of higher strain show slightly lower PGA values, and regions of lower strain show slightly higher PGA values compared to the average. This is the reverse for Case 2, the power-law models. This is directly related to the modelled $a$ value: The linear model gives relatively higher $a$ values at lower strains, and lower $a$-values at higher strains than the power-law model. This can be seen from Fig. 10 by the fact that the model fit lines cross each other at strain rate of around $7 \times 10^{-8} \mathrm{yr}^{-1}$. A comparison of hazard curves produced from these four models is shown in Fig. 16(a). Changing $M_{\max }$ does not make that much difference for a time period of $50 \mathrm{yr}$, since the larger magnitude earthquakes have a 


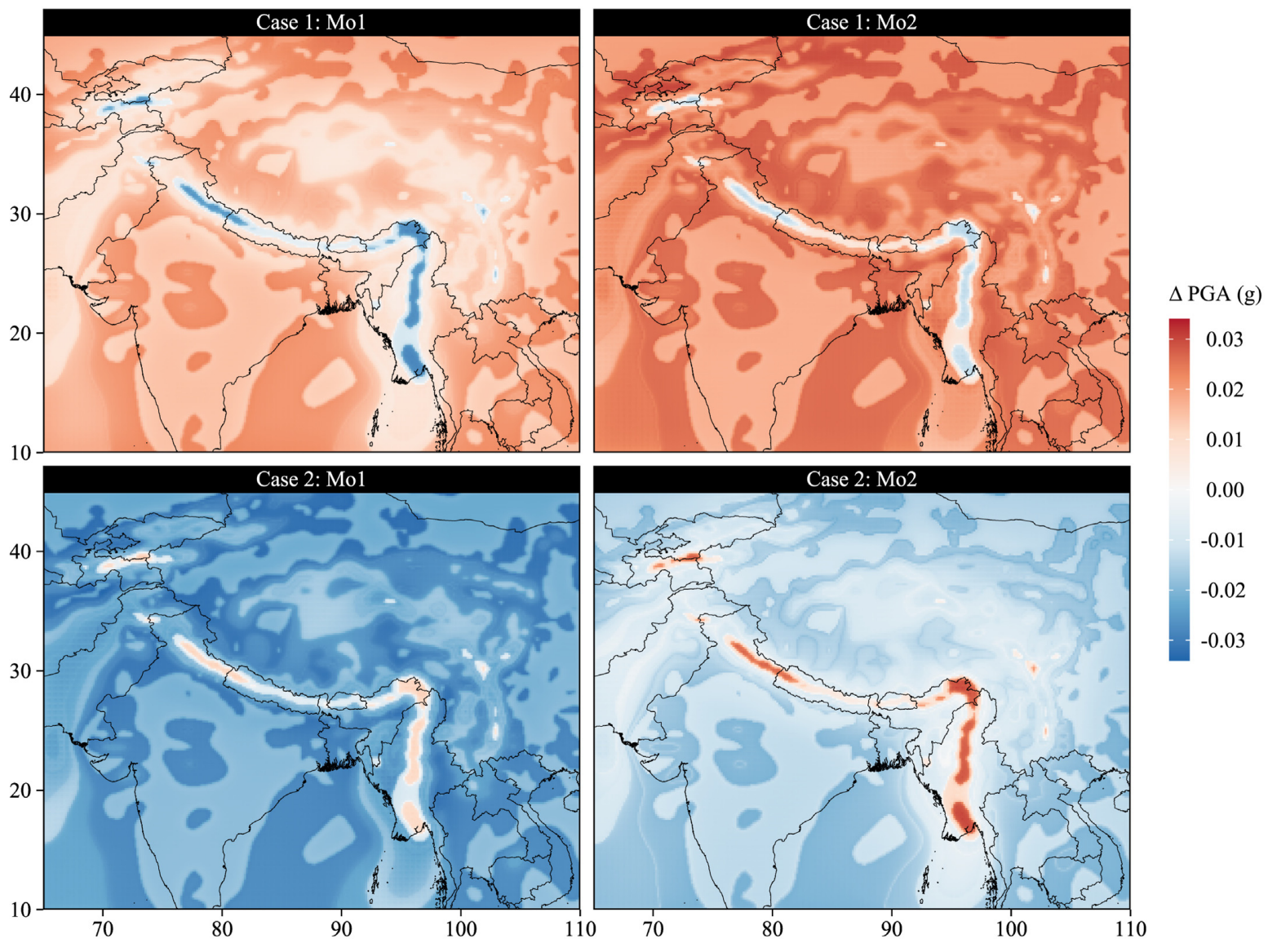

Figure 15. Comparison of the four input models with the average, shown in Fig. 14. Case 1 is the linear model, and Case 2 is the power-law model. Mo1 is using the original moment, and Mo2 is using twice the original moment, which means $M_{\max }$ changes from 8.7 to 9.4.
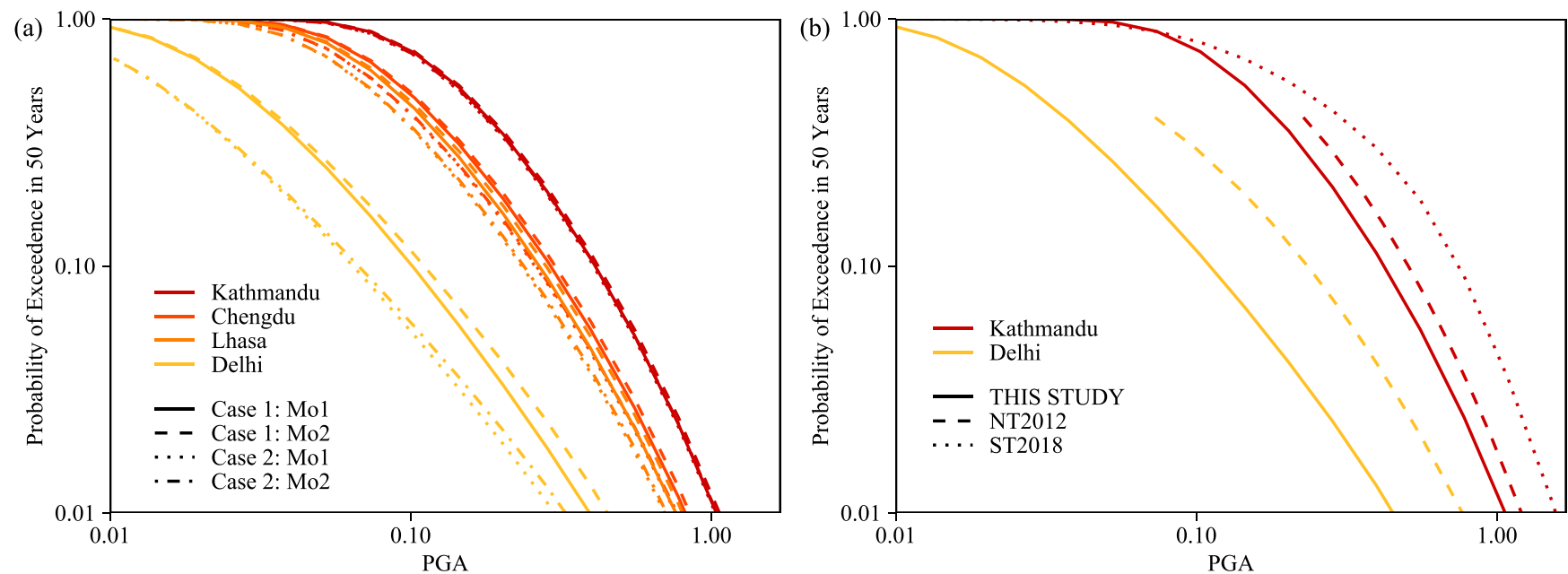

Figure 16. (a) Hazard curves calculated for four major cities from the four separate seismic hazard model presented here, with locations marked on Fig. 14. (b) Comparison of our average model with the Nath \& Thingbaijam (2012) study (NT2012), which is the basis of the GEM model for the Indian subcontinent, and the local study of Nepal by Stevens et al. (2018) (ST2018).

longer recurrence time, and very low chance of occurring in the 50-yr period. The Case 1 (linear) versus Case 2 (non-linear) model makes more of a difference, especially in the low strain rate areas (where Delhi is), since in the non-linear model, the $a$-value is a lot lower here than in the linear model. At the higher strain rate areas, the $a$-values from the different models are more similar, though slightly higher for Case 2 . 

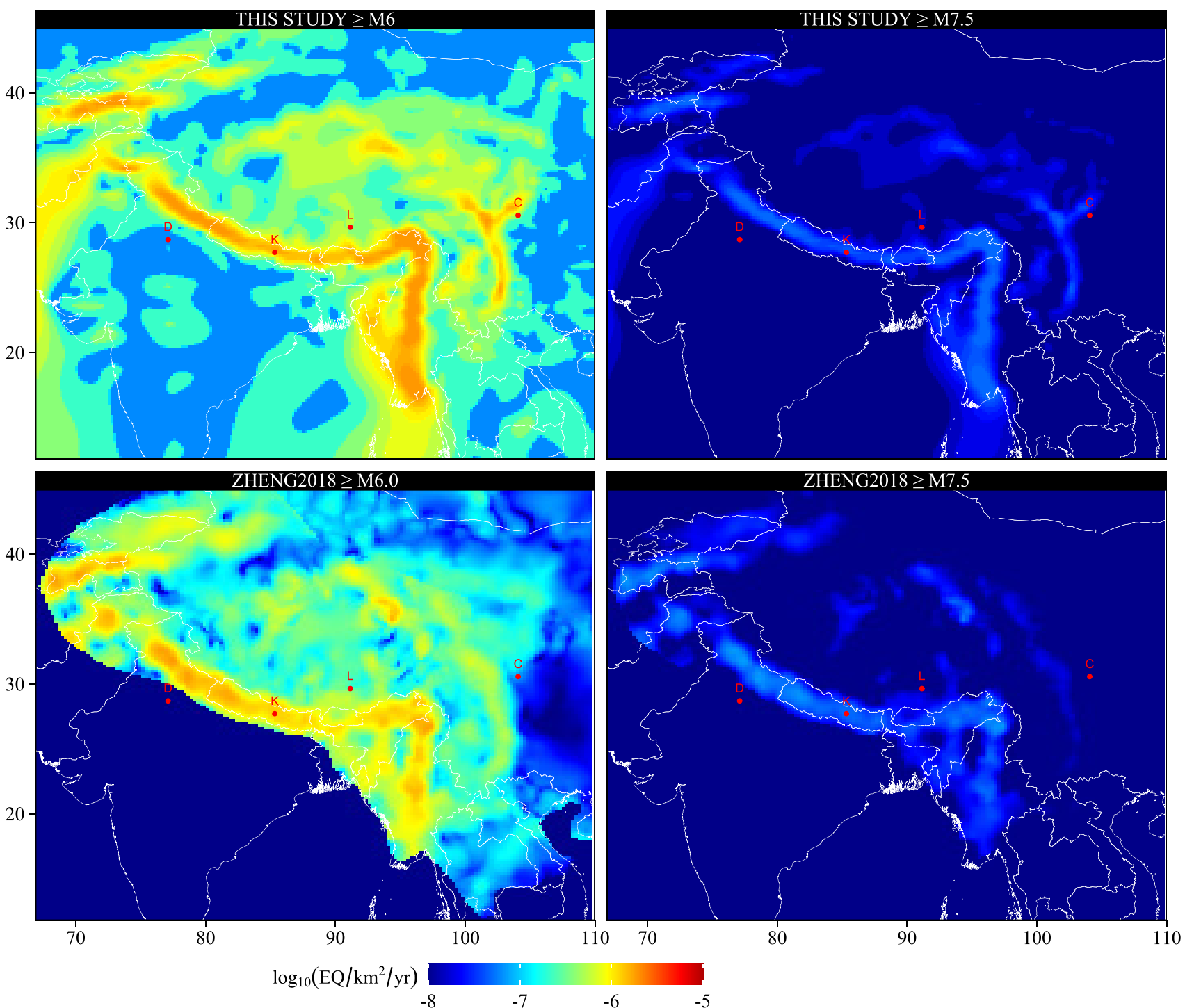

Figure 17. Comparison of our seismicity model with that of Zheng et al. (2018). We compare the density of $M_{\mathrm{w}} \geq 6$ and $M_{\mathrm{w}} \geq 7.5$ earthquake rate (number of earthquakes per $\mathrm{km}^{2}$ per year) predicted by the two models. $\mathrm{D}=$ Delhi, $\mathrm{K}=$ Kathmandu, $\mathrm{L}=$ Lhasa, $\mathrm{C}=$ Chengdu.

\subsection{Comparison with other studies}

Our seismicity forecast of might be compared with the forecast of Zheng et al. (2018) for the Tibetan region (Fig. 17) who also based their forecast on geodetic strain rates. They used the SHIFT (Seismic Hazard Inferred from Tectonics) methodology (e.g. Bird \& Liu 2007; Bird et al. 2010). The SHIFT methodology is originally based on the Global Strain Rate Map (GSRM, Kreemer et al. (2003)), which along with GPS velocities, uses geological strain rates from faults and constrains the style of the strain rate tensor from moment tensors of shallow earthquakes. Two key hypothesises of SHIFT are 1: long-term seismic moment is about that computed using the coupled seismogenic thickness of most comparable type of plate boundary and 2: the long-term earthquake rate is about that computed from its moment rate by using the frequency-magnitude distribution of the most comparable type of plate boundary. This involves separating the deforming regions into seven different tectonic classes, as defined by Bird (2003): ridge-transform faults, diffuse oceanic, subduction, continental convergent faults, continental rift and continental transform faults and also 'non-deforming' zones. Each class is assigned a seismogenic thickness and a frequency-magnitude distribution of earthquakes represented by a exponentially tapered $\mathrm{G}-\mathrm{R}$ distribution. A corner magnitude is assigned to each class to represent the tapering. Note that the exponential tapering is different from the truncation adopted in our study in that it formally allows unbounded magnitudes.

Using the SHIFT model, but based on new GPS data, Zheng et al. (2018) applied the methodology but using the regional geodetic strain rate model of Zheng et al. (2018) instead of the Global Strain Rate Model of Kreemer et al. (2003). Their input GPS data is similar to ours. They additionally made use of three of the different tectonic classes defined in SHIFT for Tibet, and considered India to be a 'non'deforming' zone. They then recalibrated the empirical constants used so that the estimated moment release matches that observed. The corner magnitudes used by Zheng et al. (2018) are $8.46_{-0.39}^{+0.21}, 8.01_{-0.21}^{+0.47}$ and $7.64_{-0.26}^{+0.76}$ for continental convergent, transform and rift-boundary areas, respectively. 

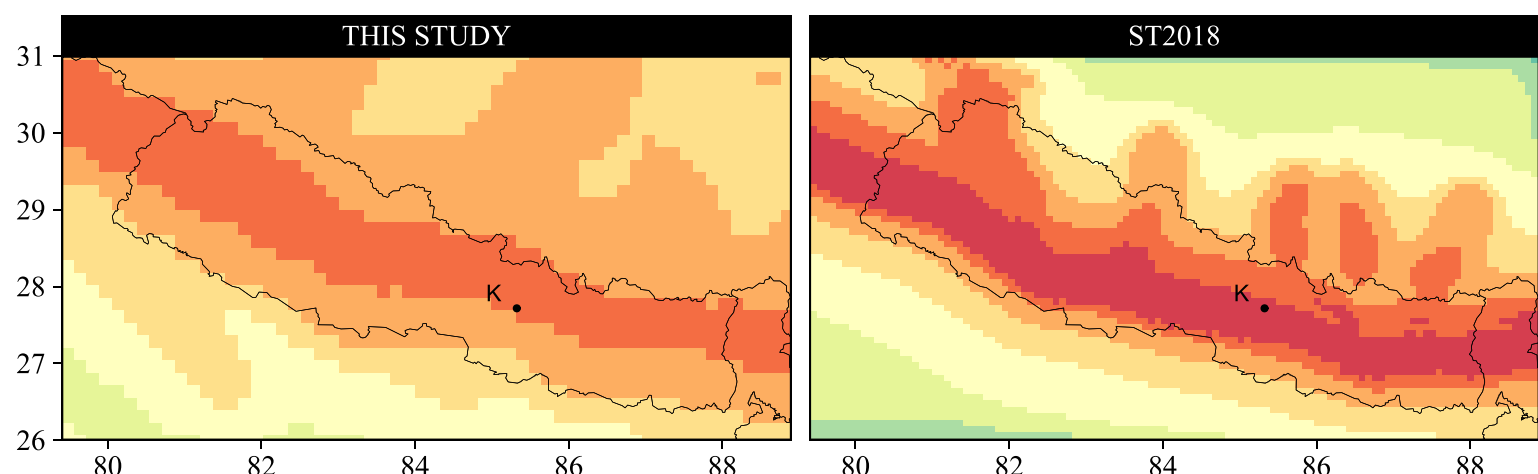

PGA (g)

0.55-0.90

$0.35-0.55$

0.20-0.35

0.13-0.20

0.08-0.13

0.05-0.08

0.03-0.05

$0.02-0.03$
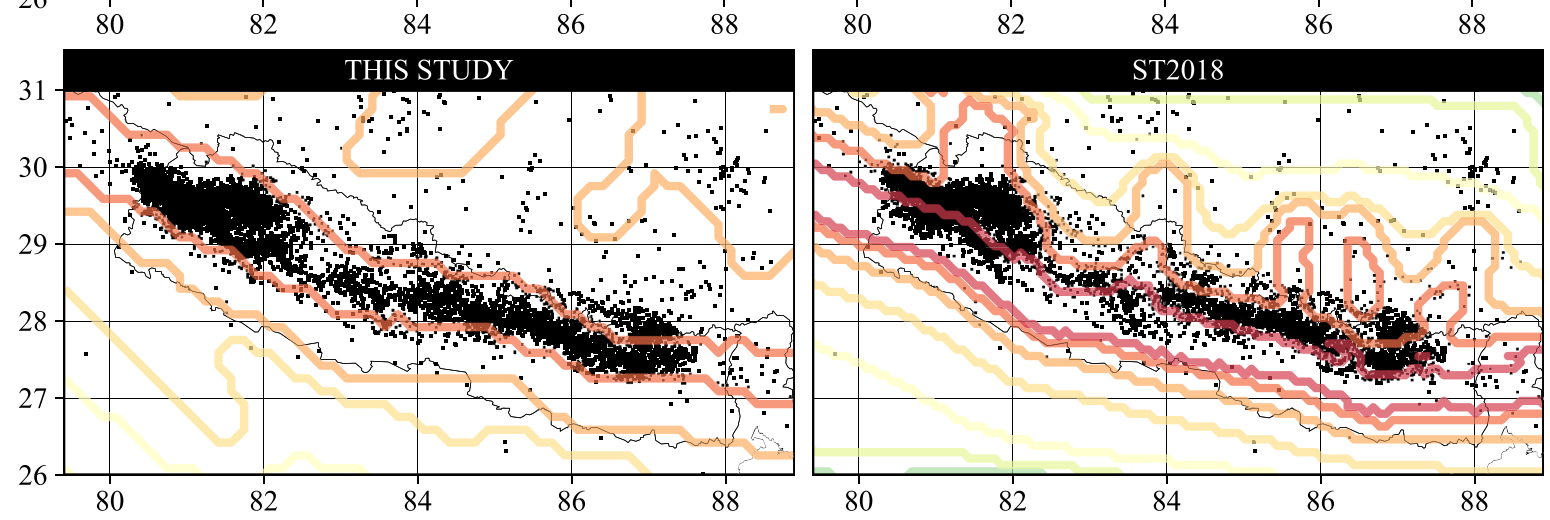

PGA (g)

$=0.55$

$=0.35$

$-0.20$

0.13

0.08

0.05

$-0.03$

Figure 18. Comparison of our hazard model in Nepal with that of Stevens et al. (2018) (ST2018). K= Kathmandu. Lower plots shows declustered earthquakes from the 10-yr catalogue plus, covering Nepal, a relocated catalogue of the National Seismological Centre (NSC), recorded between 1995 and 2001 ( $0.8 \leq M$ $\leq 5.5$ ) (Ader et al. 2012; Rajaure et al. 2013).

Our method predicts seismicity rate very similar to those based on the SHIFT methodology as can be seem for $M>6$. and $M>7.5$ (Fig. 17). The main difference is that our methodology does predict a non-negligible hazard level within stable India, which is more consistent with the historical records. The other more minor differences are essentially due to the different strain rate models used as input. This comparison shows that the simple conversion of strain rate to seismicity rate based on the correlation between the second invariant of the strain rate tensor adopted in our study, yields about the same results that the SHIFT methodology. Our approach is simpler to implement as it does not require any tectonic zoning and the calibration is straightforward.

It is also instructive to compare hazard maps and hazard curves predicted by our model with those based on the GEM model for this region (Pagani et al. (2018), Fig. 14b). This model is based on the studies of Nath \& Thingbaijam (2012) for South Asia, and Anon. (2015) for China. The South Asia section is based on area-sources, with $a, b$ and $M_{\max }$ determined within roughly 50 different tectonic areas, with $M_{\max }$ varying from 6 to 9.4 in the different regions. The China section is based on both area and known fault zones. The hazard maps derived from GEM and our model are broadly similar. The main difference is that the GEM map shows zones of localized higher level of hazards that correlate with the known active faults. By contrast our model yields a more diffuse pattern because the actives faults were actually not included. Also, all earthquake in our approach are treated as point sources, independently of their size and local tectonic regime. For example, an earthquake that nucleates in the Himalayan region is not constrained to rupture along the direction of the Main Himalayan Thrust. This is certainly a limitation of the very simple methodology adopted here.

We also compare the hazard estimated from our approach with the hazard estimated following a more standard PSHA approach applied to Nepal by Stevens et al. (2018). This study considers a local tectonic zoning in terms of active faults and distributed seismogenic areas. Each zone is associated with a frequency-magnitude $\mathrm{G}-\mathrm{R}$ relationship based on instrumental, historic and palaeoseismic earthquakes (see Fig. 18). We see that the shape of the higher PGA areas are similar, though in the model of Stevens et al. (2018) there is some higher hazard due to the largest earthquakes which are constrained to rupture the portion of the Main Himalayan Thrust (MHT) which is locked in the interseismic period. We note that the zone of highest hazard in our model correlates well with the pattern of seismicity recorded locally, which shows a belt of seismicity following closely the front of the High Himalaya (Fig. 18). This is a direct consequence of the fact that our model is designed to forecast epicentres, but does not account for the finite extent of large earthquake ruptures. By contrast, the zone of higher hazard in Stevens et al. (2018) is shifted southward compared to that belt of seismicity. This shift is due to the fact that the larger earthquakes are expected to be thrust events rupturing the locked portion of the MHT, which extends south of the front of the High Himalaya and is relatively silent seismically. Our model accounts for the fact that earthquakes tend to nucleate at the lower edge of the locked fault zones, as this is where stress in building up in the interseismic period (Cattin \& Avouac 2000; Ader et al. 2012). However, because earthquakes are treated as point sources, our model ignores that large ruptures can propagate into locked fault zones. The fact that the locked portion of the MHT is clearly distinct from the zone of earthquake triggered by interseismic loading is due to the particular low dip angle of the MHT which is 
estimated to about $7^{\circ}$ on average (Elliott et al. 2016) and to the large width of the interseismic locked zone which is estimated to about $110 \mathrm{~km}$ on average (Stevens \& Avouac 2016).

The two models yield also different results for southern Tibet, as Stevens et al. (2018) included specific seismogenic zones to account for the NS trending active normal faults there. By contrast the interseismic strain pattern associated with these normal faults is not resolved with the geodetic data, so the seismic hazard predicted with our model is more uniform there.

We compare the hazard curves at Delhi and Kathmandu calculated from our model with those of Nath \& Thingbaijam (2012) and Stevens et al. (2018) in Fig. 16b). For Kathmandu, the hazard curves are higher, though similar, in both the other models, related to the explicit input of the MHT. For Delhi, the model of Nath \& Thingbaijam (2012), shows a significantly higher hazard curve. From Fig. 14 we see that in their model, Delhi is in a bullseye of higher hazard, since in their model this tectonic region had more earthquakes than nearby. In our model, Delhi is in a region of lower hazard, with hazard decreasing fairly smoothly away from the Himalayas. With the SHIFT method, all areas that are classified as 'plate interiors' are assumed to have the same seismicity, based on the worldwide seismicity in these areas. This leads to a much lower seismicity rate south of the Himalaya, which would yield an even lower hazard level than our model for peninsular India, and for Delhi in particular (see Fig. 17).

This section shows that, despite in simplicity, our methodology leads to seismicity models and earthquake forecast similar to the SHIFT methodology, and that hazard maps and hazard curves derived from our method are quite similar to those based on standard PSHA methods. The simplicity and low computational cost of our approach is advantageous as it allows easy updating, sensitivity testing and uncertainty quantification.

The main limitations of our approach are that active faults are not explicitly taken into account, and that earthquakes are treated as point sources, leading to potential bias in the hazard maps due to the fact that large ruptures can extend into locked zone where geodetic strain rate is small. These limitations could be overcome pending some adaptations which have not been implemented here. For example, active faults could be included in addition to geodetic strain rates and seismicity by using as a input to the method not directly the measured geodetic strain rate but some model on interseismic loading based on the joined inversion of geodetic and quaternary slip rates using some elastic block model formalism (Meade \& Loveless 2009). Similarly, the finite extent of earthquake sources could be accounted for by taking into account the local tectonic context. These adaptations would come at a computational cost and create a less simple framework that would make sensitivity testing and uncertainty quantifications more difficult.

\section{CONCLUSION}

Our study shows that seismicity rate determined using small and moderate independent earthquakes correlates well with geodetic strain rates over the India-Asia collision zone. Therefore, we can use the strain rate from the GPS together with the instrumental seismicity to produce a probabilistic earthquake model which can be used as an input for seismic hazard assessment. We made the choice of a truncated G-R distribution to simplify the algebra. The analysis could be adapted to the more robust assumption of tapered frequency-magnitude distribution, assuming for example exponential tapering (Kagan 2002a). We expect that this would affect only the very low probability tail of hazard curves.

The rationale behind our method is that earthquakes are triggered by interseismic loading, and that the moment released by earthquakes balances the deficit of moment that builds in the interseismic period. Interseismic loading is assumed stationary. Our method yields results very similar to those obtained with SHIFT (e.g., Bird \& Liu 2007; Zheng et al. 2018), regarding seismicity rates forecast, and standard PSHA for hazard assessment (e.g. Stevens et al. 2018).

In contrast to current practice in PSHA, there is no subjectivity in delineating different seismogenic zones, they are determined based only on the geodetic strain rates, and it is simple to see how the inputs influence the results. This is an advantage, as the choice of sources is subjective and differs from model to model. Our method is more systematic and easier to update than the SHIFT or GEM approach (which requires combining different models which are each difficult to rederive and update). The method presented here does not make use of information such as the active faults maps, fault slip rates or palaeoseismic results, which are commonly used in PSHA. We have deliberately not used data other than seismicity catalogues and GPS. The information on fault kinematics could easily be incorporated, although at the cost of complicating the framework, by using as an input to our method the interseismic strain rates estimated from a block model constrained by both geodetic rates and geological slip rates.

Our simple method for PSHA can be applied in areas with sufficient geodetic coverage and seismicity monitoring, both of which are continuously improving. However, before use, it is necessary to be sure that the GPS used are representative of the long-term deformation, and that the elastic strain released by seismicity is consistent with geodetic strain rate measured from geodesy. This method applies to active areas, and probably does not work so well in areas of low strain rate $\left(<2 \times 10^{-8} \mathrm{yr}^{-1}\right)$, where the hypothesis that the elastic strain available to drive future earthquakes can be estimated based on modern strain rate might not hold.

\section{ACKNOWLEDGEMENTS}

We would like to thank Peter Bird and Chris Rollins for constructive and detailed reviews of this manuscript. VLS was supported by the Claude Leon Foundation. This work was partially supported by NSF award EAR-1821853. 


\section{DATA AVAILABILITY}

No new data were generated or analysed in support of this research. All data used in this study is already publicly available.

\section{REFERENCES}

Ader, T. et al., 2012. Convergence rate across the Nepal Himalaya and interseismic coupling on the Main Himalayan Thrust: implications for seismic hazard, J. geophys. Res., 117(B4), doi:10.1029/2011JB009071.

Ader, T.J., Lapusta, N., Avouac, J.P. \& Ampuero, J.P., 2014. Response of rate-and-state seismogenic faults to harmonic shear-stress perturbations, Geophys. J. Int., 198(1), 385-413.

Aki, K., 1965. Maximum Likelihood estimate of $\mathrm{b}$ in the formula $\log \mathrm{N}=\mathrm{a}-$ bM and its confidence limits., Bull. Earthq. Res Inst.,Tokyo Univ., 43, 237-239.

Allen, T.I. \& Wald, D.J., 2009. On the use of high-resolution topographic data as a proxy for seismic site conditions (VS30), Bull. seism. Soc. Am., 99(2A), 935-943.

Amelung, F. \& King, G., 1997. Large-scale tectonic deformation inferred from small earthquakes, Nature, 386(6626), 702-705.

, Anon., 2015. China seismic zoning map, Tech. rep., General Administration of Quality Supervision, Inspection and Quarantine of the People's Republic of China, China National Standardization Management Committee, Beijing.

Avouac, J.-P., 2015. From geodetic imaging of seismic and aseismic fault slip to dynamic modeling of the seismic cycle, Annu. Rev. Earth planet. Sci., 43(1), 233-271.

Beeler, N.M., 2003. Why earthquakes correlate weakly with the solid Earth tides: effects of periodic stress on the rate and probability of earthquake occurrence, J. geophys. Res., 108(B8), doi:10.1029/2001JB001518.

Bender, B., 1983. Maximum likelihood estimation of $\mathrm{b}$ values for magnitude grouped data, Bull. seism. Soc. Am., 73(3), 831-851.

Bennett, R.A., Friedrich, A.M. \& Furlong, K.P., 2004. Codependent histories of the San Andreas and San Jacinto fault zones from inversion of fault displacement rates, Geology, 32(11), 961-964.

Bettinelli, P., Avouac, J.-P., Flouzat, M., Bollinger, L., Ramillien, G., Rajaure, S. \& Sapkota, S., 2008. Seasonal variations of seismicity and geodetic strain in the Himalaya induced by surface hydrology, Earth planet. Sci. Lett., 266(3-4), 332-344.

Bird, P., 2003. An updated digital model of plate boundaries, Geochem., Geophys. Geosyst., 4(3), doi:10.1029/2001GC000252.

Bird, P., 2009. Long-term fault slip rates, distributed deformation rates, and forecast of seismicity in the western United States from joint fitting of community geologic, geodetic, and stress direction data sets, J. geophys. Res., 114(B11), doi:10.1029/2009JB006317.

Bird, P. \& Liu, Z., 2007. Seismic hazard inferred from tectonics: California, Seismol. Res. Lett., 78(1), 37-48.

Bird, P., Kreemer, C. \& Holt, W.E., 2010. A long-term forecast of shallow seismicity based on the global strain rate map, Seismol. Res. Lett., 81(2), 184-194.

Bird, P., Jackson, D.D., Kagan, Y.Y., Kreemer, C. \& Stein, R.S., 2015. GEAR1: a global earthquake activity rate model constructed from geodetic strain rates and smoothed seismicity, Bull. seism. Soc. Am., 105(5), 2538-2554.

Blewitt, G., 2007. GPS and space-based geodetic methods, in Treatise on Geophysics, pp. 351-390, ed. Schubert, G., Elsevier.

Bollinger, L., Avouac, J.P., Beyssac, O., Catlos, E.J., Harrison, T.M., Grove, M., Goffé, B. \& Sapkota, S., 2004. Thermal structure and exhumation history of the Lesser Himalaya in central Nepal, Tectonics, 23(5), doi:10.1029/2003TC001564.

Bollinger, L. et al., 2014. Estimating the return times of great Himalayan earthquakes in eastern Nepal: evidence from the Patu and Bardibas strands of the Main Frontal Thrust, J. geophys. Res., 119(9), 7123-7163.

Boore, D.M., Stewart, J.P., Seyhan, E. \& Atkinson, G.M., 2014. NGA-West2 equations for predicting PGA, PGV, and 5 per cent damped PSA for shallow crustal earthquakes, Earthq. Spectra, 30(3), $1057-1085$.
Bungum, H., Olesen, O., Pascal, C., Gibbons, S., Lindholm, C. \& VestØl, O., 2010. To what extent is the present seismicity of Norway driven by post-glacial rebound?, J. Geol. Soc. Lond., 167(2), 373-384.

Calais, E., Freed, A.M., Van Arsdale, R. \& Stein, S., 2010. Triggering of New Madrid seismicity by late-Pleistocene erosion, Nature, 466(7306), 608-611.

Calais, E., Camelbeeck, T., Stein, S., Liu, M. \& Craig, T.J., 2016. A new paradigm for large earthquakes in stable continental plate interiors, Geophys. Res. Lett., 43(20), 10 621-10 637.

Carafa, M.M., Valensise, G. \& Bird, P., 2017. Assessing the seismic coupling of shallow continental faults and its impact on seismic hazard estimates: a case-study from Italy, Geophys. J. Int., 209(1), 32-47.

Cattin, R. \& Avouac, J.P., 2000. Modeling mountain building and the seismic cycle in the Himalaya of Nepal, J. geophys. Res., 105(B6), 13 389-13 407.

Chaikin, G.M., 1974. An algorithm for high-speed curve generation, Comput. Graph. Image Process., 3(4), 346-349.

Chen, W.-P. \& Molnar, P., 1977. Seismic moments of major earthquakes and the average rate of slip in central Asia, J. geophys. Res., 82(20), 2945-2969.

Chéry, J., Carretier, S. \& Ritz, J.F., 2001. Postseismic stress transfer explains time clustering of large earthquakes in Mongolia, Earth planet. Sci. Lett., 194(1-2), 277-286.

Chiou, B. S.-J. \& Youngs, R.R., 2014. Update of the Chiou and Youngs NGA model for the average horizontal component of peak ground motion and response spectra, Earthq. Spectra, 30(3), 1117-1153.

Craig, T.J., Calais, E., Fleitout, L., Bollinger, L. \& Scotti, O., 2016. Evidence for the release of long-term tectonic strain stored in continental interiors through intraplate earthquakes, Geophys. Res. Lett., 43(13), 6826-6836.

Crone, A.J., De Martini, P.M., Machette, M.N., Okumura, K. \& Prescott, J.R., 2003. Paleoseismicity of two historically quiescent faults in Australia: Implications for fault behavior in stable continental regions, Bull. seism. Soc. Am., 93(5), 1913-1934.

Delescluse, M. \& Chamot-Rooke, N., 2007. Instantaneous deformation and kinematics of the India-Australia Plate, Geophys. J. Int., 168(2), 818-842.

DeMets, C., Gordon, R.G. \& Argus, D.F., 2010. Geologically current plate motions, Geophys. J. Int., 181(1), 1-80.

Di Giacomo, D., Robert Engdahl, E. \& Storchak, D.A., 2018. The ISC-GEM Earthquake Catalogue (1904-2014): status after the extension project, Earth Syst. Sci. Data, 10(4), 1877-1899.

Dieterich, J., 1994. A constitutive law for rate of earthquake production and its application to earthquake clustering, J. geophys. Res., 99(B2), 2601-2618.

Dixon, T.H., Norabuena, E. \& Hotaling, L., 2003. Paleoseismology and global positioning system: earthquake-cycle effects and geodetic versus geologic fault slip rates in the Eastern California shear zone, Geology, 31(1), 55-58.

Dolan, J.F., Bowman, D.D. \& Sammis, C.G., 2007. Long-range and longterm fault interactions in Southern California, Geology, 35(9), 855-858.

Dziewonski, A.M., Chou, T.-A.A. \& Woodhouse, J.H., 1981. Determination of earthquake source parameters from waveform data for studies of global and regional seismicity., J. geophys. Res., 86(B4), 2825-2852.

Ekström, G., Nettles, M., Dziewoñski, A.M. \& Dziewoński, A.M., 2012. The global CMT project 2004-2010: centroid-moment tensors for 13,017 earthquakes, Phys. Earth planet. Inter., 200-201, 1-9.

Elliott, J.R., Walters, R.J., England, P.C., Jackson, J.A., Li, Z. \& Parsons, B., 2010. Extension on the Tibetan plateau: recent normal faulting measured by InSAR and body wave seismology, Geophys. J. Int., 183(2), 503-535.

Elliott, J.R., Jolivet, R., Gonzalez, P.J., Avouac, J.-P.P., Hollingsworth, J., Searle, M.P. \& Stevens, V.L., 2016. Himalayan megathrust geometry and relation to topography revealed by the Gorkha earthquake, Nat. Geosci, 9(2), 174-180. 
England, P. \& Molnar, P., 1997. The field of crustal velocity in Asia calculated from Quaternary rates of slip on faults, Geophys. J. Int., 130(3), 551-582.

England, P. \& Molnar, P., 2005. Late Quaternary to decadal velocity fields in Asia, J. geophys. Res., 110(B12), B12401-.

Fialko, Y., Rivera, L. \& Kanamori, H., 2005. Estimate of differential stress in the upper crust from variations in topography and strike along the San Andreas fault, Geophys. J. Int., 160(2), 527-532.

Friedrich, A.M., Lee, J., Wernicke, B.P. \& Sieh, K., 2004. Geologic context of geodetic data across a Basin and Range normal fault, Crescent Valley, Nevada, Tectonics, 23(2), doi:10.1029/2003TC001528.

Ganev, P.N., Dolan, J.F., McGill, S.F. \& Frankel, K.L., 2012. Constancy of geologic slip rate along the central Garlock fault: implications for strain accumulation and release in southern California, Geophys. J. Int., 190(2), $745-760$.

Gardner, J.K. \& Knopoff, L., 1974. Is the sequence of earthquakes in Southern California, with aftershocks removed, Poissonian?, Bull. Seismol. Soc. Am., 64(5), 1363-1367.

Gerstenberger, M.C. et al., 2020. Probabilistic seismic hazard analysis at Regional and National Scales: state of the art and future challenges, Rev. Geophys., 58(2),

Gutenberg, B. \& Richter, C.F., 1944. Frequency of earthquakes in California, Bull. seism. Soc. Am., 34(4), 185-188.

Haines, A.J. \& Holt, W.E., 1993. A procedure for obtaining the complete horizontal motions within zones of distributed deformation from the inversion of strain rate data, J. geophys. Res., 98(B7), 12 057-12 082.

Hainzl, S. \& Christophersen, A., 2017. Testing alternative temporal aftershock decay functions in an ETAS framework, Geophys. J. Int., 210(2), 585-593.

Hardebeck, J.L. \& Hauksson, E., 2001. Crustal stress field in southern California and its implications for fault mechanics, J. geophys. Res., 106(B10), $21859-21882$.

Heimisson, E.R. \& Segall, P., 2018. Constitutive law for earthquake production based on rate-and-state friction: Dieterich 1994 revisited, J. geophys. Res., 123(5), 4141-4156.

Helmstetter, A., Kagan, Y.Y. \& Jackson, D.D., 2006. Comparison of shortterm and time-dependent earthquake forecast models for southern California, Bull. seism. Soc. Am., 96(1), 90-106.

Holt, W.E., Li, M. \& Haines, A.J., 1995. Earthquake strain rates and instantaneous relative motions within central and eastern Asia, Geophys. J. Int., 122(2), 569-593.

Holt, W.E., Chamot-Rooke, N., Le Pichon, X., Haines, A.J., Shen-Tu, B. \& Ren, J., 2000. Velocity field in Asia inferred from Quaternary fault slip rates and Global Positioning System observations, J. geophys. Res., 105(B8), 19 185-19209.

Hsu, Y.-J. et al., 2006. Frictional afterslip following the 2005 Nias-Simeulue Earthquake, Sumatra, Science, 312(5782), 1921-1926.

International Seismological Centre, 2013. On-line Bulletin, https://doi.org/ 10.31905/D808B830.

Johnson, C.W., Fu, Y. \& Bürgmann, R., 2017. Seasonal water storage, stress modulation, and California seismicity, Science, 356(6343), $1161-1164$

Kagan, Y.Y., 1997. Seismic moment-frequency relation for shallow earthquakes: regional comparison, J. geophys. Res. Solid Earth, 102(B2), 2835-2852.

Kagan, Y.Y., 2002a. Seismic moment distribution revisited: I. Statistical results, Geophys. J. Int., 148(3), 520-541.

Kagan, Y.Y., 2002b. Seismic moment distribution revisited: $\{$ II $\}$ Moment conservation principle, Geophys. J. Int., 149(3), 731-754.

Kanamori, H. \& Brodsky, E.E., 2004. The physics of earthquakes, Reports Prog. Phys., 67(8), 1429.

Keiding, M., Kreemer, C., Lindholm, C., Gradmann, S., Olesen, O. \& Kierulf, H., 2015. A comparison of strain rates and seismicity for Fennoscandia: depth dependency of deformation from glacial isostatic adjustment, Geophys. J. Int., 202(2), 1021-1028.

Kenner, S.J. \& Simons, M., 2005. Temporal clustering of major earthquakes along individual faults due to post-seismic reloading, Geophys. J. Int., 160(1), 179-194.
Kostrov, V., 1974. Seismic moment and energy of earthquakes, and seismic flow of rock, Phys. Solid Earth, 1, 13-21.

Kreemer, C., Holt, W.E. \& Haines, A.J., 2002. The global moment rate distribution within plate boundary zones, in Plate Boundary Zone, Geodynamics Series, pp. 173-190, eds Stein, S. \& Freymueller, J.T., American Geophysical Union.

Kreemer, C., Holt, W.E. \& Haines, A.J., 2003. An integrated global model of present-day plate motions and plate boundary deformation, Geophys. J. Int., 154(1), 8-34.

Kumar, S., Wesnousky, S.G., Rockwell, T.K., Briggs, R.W., Thakur, V.C. \& Jayangondaperumal, R., 2006. Paleoseismic evidence of great surface rupture earthquakes along the Indian Himalaya, J. geophys. Res., 111(B3), doi:10.1029/2004JB003309.

Kumar, S., Wesnousky, S.G., Jayangondaperumal, R., Nakata, T., Kumahara, Y. \& Singh, V., 2010. Paleoseismological evidence of surface faulting along the northeastern Himalayan front, India: Timing, size, and spatial extent of great earthquakes, J. geophys. Res., 115(B12), doi:10.1029/2009JB006789.

Lange, D., Bedford, J.R., Moreno, M., Tilmann, F., Baez, J.C., Bevis, M. \& Kruger, F., 2014. Comparison of postseismic afterslip models with aftershock seismicity for three subduction-zone earthquakes: Nias 2005, Maule 2010 and Tohoku 2011, Geophys. J. Int., 199(2), 784-799.

Lavé, J., Yule, D., Sapkota, S., Basant, K., Madden, C., Attal, M. \& Pandey, R., 2005. Evidence for a great medieval earthquake ( 1100 A.D.) in the central Himalayas, Nepal, Science, 307(5713), 1302-1305.

Liu, M. \& Stein, S., 2016. Mid-continental earthquakes: spatiotemporal occurrences, causes, and hazards, Earth-Sci. Rev., 162, 364-386.

Liu-Zeng, J. et al., 2009. Co-seismic ruptures of the 12 May 2008, Ms 8.0 Wenchuan earthquake, Sichuan: east-west crustal shortening on oblique, parallel thrusts along the eastern edge of Tibet, Earth planet. Sci. Lett., 286(3-4), 355-370.

Luen, B. \& Stark, P.B., 2012. Poisson tests of declustered catalogues, Geophys. J. Int., 189(1), 691-700.

Lundgren, P., Hetland, E.A., Liu, Z. \& Fielding, E.J., 2009. Southern San Andreas-San Jacinto fault system slip rates estimated from earthquake cycle models constrained by GPS and interferometric synthetic aperture radar observations, J. geophys. Res., 114(B2), doi:10.1029/2008JB005996.

Marsan, D. \& Lengliné, O., 2008. Extending earthquakes' reach through cascading, Science, 319(5866), 1076-1079.

Marzocchi, W. \& Sandri, L., 2003. A review and new insights on the estimation of the b-value and its uncertainty, Ann. Geophys., 46(6), $1271-1282$.

Masson, F., Chéry, J., Hatzfeld, D., Martinod, J., Vernant, P., Tavakoli, F. \& Ghafory-Ashtiani, M., 2005. Seismic versus aseismic deformation in Iran inferred from earthquakes and geodetic data, Geophys. J. Int., 160(1), 217-226.

Meade, B.J. \& Hager, B.H., 2005. Block models of crustal motion in southern California constrained by GPS measurements, J. geophys. Res., 110(B3), doi:10.1029/2004JB003209.

Meade, B.J. \& Loveless, J.P., 2009. Block modeling with connected faultnetwork geometries and a linear elastic coupling estimator in spherical coordinates, Bull. seism. Soc. Am., 99(6), 3124-3139.

Meade, B.J., Klinger, Y. \& Hetland, E.A., 2013. Inference of multiple earthquake cycle relaxation timescales from irregular geodetic sampling of interseismic deformation, Bull. seism. Soc. Am., 103(5), 2824-2835.

Molnar, P. \& Lyon-Caent, H., 1989. Fault plane solutions of earthquakes and active tectonics of the Tibetan Plateau and its margins, Geophys. J. Int., 99(1), 123-154.

Molnar, P. \& Qidong, D., 1984. Faulting associated with large earthquakes and the average rate of deformation in central and eastern Asia, J. geophys. Res., 89(B7), 6203-6227.

Nath, S.K. \& Thingbaijam, K.K.S., 2012. Probabilistic seismic hazard assessment of India, Seismol. Res. Lett., 83(1), 135-149.

Newman, A., Stein, S., Weber, J., Engeln, J., Mao, A. \& Dixon, T., 1999. Slow deformation and lower seismic hazard at the New Madrid seismic zone, Science, 284(5414), 619-621. 
Niemi, N.A., Wernicke, B.P., Friedrich, A.M., Simons, M., Bennett, R.A. \& Davis, J.L., 2004. BARGEN continuous GPS data across the eastern Basin and Range province, and implications for fault system dynamics, Geophys. J. Int., 159(3), 842-862.

Ogata, Y., 1988. Statistical models for earthquake occurrences and residual analysis for point processes, J. Am. Stat. Assoc., 83(401), 9-27.

Oskin, M., Perg, L., Shelef, E., Strane, M., Gurney, E., Singer, B. \& Zhang, X., 2008. Elevated shear zone loading rate during an earthquake cluster in eastern California, Geology, 36(6), 507-510.

Pagani, M. et al., 2014. OpenQuake engine: an open hazard (and risk) software for the global earthquake model, Seismol. Res. Lett., 85(3), 692-702.

Pagani, M. et al., 2018. Global Earthquake Model (GEM) Seismic Hazard Map (version 2018.1-December 2018), doi:10.13117/GEM-GLOBALSEISMIC-HAZARD-MAP-2018.

Peltzer, G., Crampé, F., Hensley, S. \& Rosen, P., 2001. Transient strain accumulation and fault interaction in the Eastern California shear zone, Geology, 29(11), 975-978.

Perfettini, H. \& Avouac, J.-P., 2004a. Postseismic relaxation driven by brittle creep: a possible mechanism to reconcile geodetic measurements and the decay rate of aftershocks, application to the Chi-Chi earthquake, Taiwan, J. geophys. Res., 109(B2), doi:10.1029/2003JB002488.

Perfettini, H. \& Avouac, J.-P., 2004b. Stress transfer and strain rate variations during the seismic cycle, J. geophys. Res., 109(B6), doi:10.1029/2003JB002917.

Rajaure, S. et al., 2013. Double difference relocation of local earthquakes in the Nepal Himalaya, J. Nepal Geol. Soc., 46, 133-142.

Reasenberg, P., 1985. Second-order moment of central California seismicity, 1969-1982, J. geophys. Res., 90(B7), 5479-5495.

Reid, H.F., 1910. The Mechanics of the Earthquake: The California Earthquake of 18 April, 1906, 2, Carnegie Institution, Washington, DC.

Rhoades, D.A., Christophersen, A. \& Gerstenberger, M.C., 2017. Multiplicative earthquake likelihood models incorporating strain rates, Geophys. $J$. Int., 208(3), 1764-1774.

Riguzzi, F., Crespi, M., Devoti, R., Doglioni, C., Pietrantonio, G. \& Pisani, A.R., 2012. Geodetic strain rate and earthquake size: new clues for seismic hazard studies, Phys. Earth planet. Inter., 206-207, 67-75.

Ripley, B.D., 1977. Modelling spatial patterns, J. R. Stat. Soc, B, 39(2), 172-192.

Rivera, L. \& Kanamori, H., 2002. Spatial heterogeneity of tectonic stress and friction in the crust, Geophys. Res. Lett., 29(6), 121-124.

Rollins, C. \& Avouac, J.P., 2019. A geodesy- and seismicity-based local earthquake likelihood model for Central Los Angeles, Geophys. Res. Lett., 46(6), 3153-3162.

Rong, Y., Jackson, D.D., Magistrale, H. \& Goldfinger, C., 2014. Magnitude limits of subduction zone earthquakes, Bull. seism. Soc. Am., 104(5), 2359-2377.

Salditch, L., Stein, S., Neely, J., Spencer, B.D., Brooks, E.M., Agnon, A. \& Liu, M., 2020. Earthquake supercycles and long-term fault memory, Tectonophysics, 774,

Scordilis, E.M., 2006. Empirical global relations converting $\mathrm{M}_{\mathrm{S}}$ and $\mathrm{m}_{\mathrm{b}}$ to moment magnitude, J. Seismol., 10(2), 225-236.

Shen, Z.-K., Jackson, D.D. \& Kagan, Y.Y., 2007. Implications of geodetic strain rate for future earthquakes, with a five-year forecast of M5 earthquakes in Southern California, Seismol. Res. Lett., 78(1), 116-120.

Shen, Z.K., Wang, M., Zeng, Y. \& Wang, F., 2015. Optimal interpolation of spatially discretized geodetic data, Bull. seism. Soc. Am., 105(4), 21172127.

Shen-Tu, B., Holt, W.E. \& Haines, A.J., 1998. Contemporary kinematics of the western United States determined from earthquake moment tensors, very long baseline interferometry, and GPS observations, J. geophys. Res., 103(B8), 18 087-18 117.

Shi, Y. \& Bolt, B.A., 1982. The standard error of the magnitude-frequency b value, Bull. seism. Soc. Am., 72(5), 1677-1687.

Sone Aung, P., Satirapod, C. \& Andrei, C.O., 2016. Sagaing fault slip and deformation in Myanmar observed by continuous GPS measurements, Geod. Geodyn., 7(1), 56-63.
Steer, P., Simoes, M., Cattin, R. \& Shyu, J.B.H., 2014. Erosion influences the seismicity of active thrust faults, Nat. Commun., 5, doi:10.1038/ncomms6564.

Stein, S. \& Liu, M., 2009. Long aftershock sequences within continents and implications for earthquake hazard assessment, Nature, 462(7269), 87-89.

Stevens, V. \& Avouac, J.-P., 2016. Millenary $\mathrm{M}_{\mathrm{w}}>9.0$ earthquakes required by geodetic strain in the Himalaya, Geophys. Res. Lett., 43(3), $1118-1123$.

Stevens, V.L. \& Avouac, J.P., 2015. Interseismic coupling on the main Himalayan thrust, Geophys. Res. Lett., 42(14), 5828-5837.

Stevens, V.L., Shrestha, S.N. \& Maharjan, D.K., 2018. Probabilistic seismic hazard assessment of Nepal, Bull. seism. Soc. Am., 108(6), 3488-3510.

Storchak, D.A., Giacomo, D.D., Bondár, I., Engdahl, E.R., Harris, J., Lee, W.H., Villaseñor, A. \& Bormann, P., 2013. Public release of the ISCGEM global instrumental earthquake catalogue (1900-2009), Seismol. Res. Lett., 84(5), 810-815.

Storchak, D.A., Di Giacomo, D., Engdahl, E.R., Harris, J., Bondár, I., Lee, W.H., Bormann, P. \& Villaseñor, A., 2015. The ISC-GEM Global Instrumental Earthquake Catalogue (1900-2009): introduction, Phys. Earth planet. Inter., 239, 48-63.

Styron, R., Taylor, M. \& Okoronkwo, K., 2010. Database of active structures from the Indo-Asian collision, EOS, Trans. Am. Geophys. Un., 91(20), 181-182.

Tape, C., Musé, P., Simons, M., Dong, D. \& Webb, F., 2009. Multiscale estimation of GPS velocity fields, Geophys. J. Int., 179(2), 945-971.

Tong, X., Smith-Konter, B. \& Sandwell, D.T., 2014. Is there a discrepancy between geological and geodetic slip rates along the San Andreas Fault System?, J. geophys. Res., 119(3), 2518-2538.

Utsu, T., 1965. A method for determining the value of $\mathrm{b}$ in the formula $\log \mathrm{n}=\mathrm{a}-\mathrm{bM}$ showing the magnitude-frequency relation for earthquakes, Geophys. Bull. Hokkaido Univ. 13, 13, 99-103.

Vidale, J.E., Agnew, D.C., Johnston, M.J. \& Oppenheimer, D.H., 1998. Absence of earthquake correlation with Earth tides: an indication of high preseismic fault stress rate, J. geophys. Res., 103(10), 24 567-24 572.

Walker, R.T. et al., 2015. The Egiin Davaa prehistoric rupture, central Mongolia: a large magnitude normal faulting earthquake on a reactivated fault with little cumulative slip located in a slowly deforming intraplate setting, Geol. Soc. Lond., Spec. Publ., 432(1), 187-212.

Wang, M. \& Shen, Z.K., 2020. Present-day crustal deformation of continental China derived from GPS and its tectonic implications, J. geophys. Res., 125(2), doi:10.1029/2019JB018774.

Wang, Y., Sieh, K., Aung, T., Min, S., Khaing, S.N. \& Tun, S.T., 2011. Earthquakes and slip rate of the southern Sagaing fault: insights from an offset ancient fort wall, lower Burma (Myanmar), Geophys. J. Int., 185(1), 49-64.

Ward, S.N., 1998. On the consistency of earthquake moment rates, geological fault data, and space geodetic strain: the United States, Geophys. J. Int., 134(1), 172-186.

Wei, S. et al., 2010. Regional earthquakes in northern Tibetan Plateau: implications for lithospheric strength in Tibet, Geophys. Res. Lett., 37(19), doi:10.1029/2010GL044800.

Wiemer, S. \& Wyss, M., 2000. Minimum magnitude of completeness in earthquake catalogs: examples from Alaska, the Western United States, and Japan, Bull. seism. Soc. Am., 90(4), 859-869.

Zaliapin, I. \& Ben-Zion, Y., 2013. Earthquake clusters in southern California I: Identification and stability, J. geophys. Res., 118(6), 2847-2864.

Zhao, J.X. et al., 2006. Attenuation relations of strong ground motion in Japan using site classification based on predominant period, Bull. seism. Soc. Am., 96(3), 898-913.

Zheng, G. et al., 2017. Crustal deformation in the India-Eurasia collision zone from 25 years of GPS measurements, J. geophys. Res., 122(11), 9290-9312.

Zheng, G., Lou, Y., Wang, H., Geng, J. \& Shi, C., 2018. Shallow seismicity forecast for the India-Eurasia collision zone based on geodetic strain rates, Geophys. Res. Lett., 45(17), 8905-8912. 


\section{SUPPORTING INFORMATION}

Supplementary data are available at $G J I$ online.

Figure S1 Second invariant of the strain rate tensor calculated using the method of Shen et al. (2015).

Figure S2 G-R plot for both the full and declustered catalogues. We find $M_{\mathrm{c}}=4$ for both catalogues.

Figure S3 Same as Fig. 10(a), with black diamonds showing the results obtained from strain rates calculated using the method of Shen et al. (2015).

Figure S4 Coloured dots show $1 \times 10^{-8} \mathrm{yr}^{-1}$ binning, as shown in Fig. 10(a). Black triangles show the results for (a) binning of $0.5 \times$ $10^{-8} \mathrm{yr}^{-1}$ and (b) binning of $0.1 \times 10^{-8} \mathrm{yr}^{-1}$. We see that, as expected, the dispersion increases as the size of the data set in each bin decrease, but the trend remains the same, independently of bin size. Grey lines show 100000 realizations of randomized distributions for the different bin sizes. Scatter increases as the area size decreases, leading to the areas of higher strain rate, which are smaller in size, having the largest scatter. The areas of very lowest strain rate are also small, so also have large scatter.

Figure S5 Same as Fig. 10(b) but now showing results for (a) binning of $0.5 \times 10^{-8} \mathrm{yr}^{-1}$ and (b) binning of $0.1 \times 10^{-8} \mathrm{yr}^{-1}$.

Figure S6 Same as Fig. 10(a) but now comparing (a) $M_{\mathrm{c}}=4.0$ and (b) $M_{\mathrm{c}}=4.5$. Note the different scales on the $y$-axis.

Figure S7 Same as Fig. 11 but now showing black triangles for (a) binning of $0.5 \times 10^{-8} \mathrm{yr}^{-1}$ and (b) binning of $0.1 \times 10^{-8} \mathrm{yr}^{-1}$.

Figure S8 Same as Fig. 10(a) but now showing separation into areas of negative and positive first invariant of strain rate. Grey lines show 100000 realizations of randomized distributions for the number of earthquakes with a positive first invariant (3297 events). Since the spread in the randomized data is similar to the spread in the real data for the higher strain rate bins, there are too few earthquakes here in areas of positive first invariant for any trend to be significant.

Figure S9 PGA (g) for 10 per cent chance in $50 \mathrm{yr}$, with proxy VS30 from USGS (Allen \& Wald 2009).

Please note: Oxford University Press is not responsible for the content or functionality of any supporting materials supplied by the authors. Any queries (other than missing material) should be directed to the corresponding author for the paper. 